\title{
An exploration of interdisciplinary collaboration when serving students with moderate and severe disabilities at the middle and high school levels: A current snapshot of perceived barriers and opportunities
}

Sara A. Brannan

West Virginia University

Follow this and additional works at: https://researchrepository.wvu.edu/etd

\section{Recommended Citation}

Brannan, Sara A., "An exploration of interdisciplinary collaboration when serving students with moderate and severe disabilities at the middle and high school levels: A current snapshot of perceived barriers and opportunities" (2005). Graduate Theses, Dissertations, and Problem Reports. 3418.

https://researchrepository.wvu.edu/etd/3418

This Dissertation is protected by copyright and/or related rights. It has been brought to you by the The Research Repository @ WVU with permission from the rights-holder(s). You are free to use this Dissertation in any way that is permitted by the copyright and related rights legislation that applies to your use. For other uses you must obtain permission from the rights-holder(s) directly, unless additional rights are indicated by a Creative Commons license in the record and/ or on the work itself. This Dissertation has been accepted for inclusion in WVU Graduate Theses, Dissertations, and Problem Reports collection by an authorized administrator of The Research Repository @ WVU.

For more information, please contact researchrepository@mail.wvu.edu. 
An Exploration of Interdisciplinary Collaboration When Serving Students with Moderate and Severe Disabilities at the Middle and High School Levels: A Current Snapshot of

Perceived Barriers and Opportunities

\author{
Sara A. Brannan
}

Dissertation submitted to the College of Human Resources and Education at West Virginia University in partial fulfillment of the requirement for the degree of

\author{
Doctor of Education \\ in \\ Special Education
}
Barbara L. Ludlow, Ed.D., Chair Elizabeth A. Dooley, Ed.D. Samuel F. Stack, Ph.D. Sherry Wood-Shuman, Ed.D. William Reger-Nash, Ed.D.

Department of Educational Theory and Practice

\title{
Morgantown, West Virginia 2005
}

Keywords: Special Education, Collaboration, Interdisciplinary, Disabilities Copyright 2005 Sara A. Brannan 


\begin{abstract}
An Exploration of Interdisciplinary Collaboration When Serving Students with Moderate and Severe Disabilities at the Middle and High School Levels: A Current Snapshot of Perceived Barriers and Opportunities
\end{abstract}

Sara A. Brannan

This study investigated current perceptions of the barriers and the opportunities for interdisciplinary collaboration among Special Educators and Related Health Service Personnel at the middle and high school levels when serving students with moderate and severe disabilities. In order to serve individuals with moderate and severe disabilities in accordance with federal legislation and current best practice, it is important that education and related health services professionals work together collaboratively.

The design of this study combined a simple quantitative survey measure with exploratory, qualitative inquiry using a series of open-ended focus group interviews. Sampling for this research study was purposeful homogeneous sampling where the researcher intentionally selected individuals for investigating and understanding the central phenomenon. In this study, the participants were drawn from middle and secondary teachers and related service personnel employed by the Springfield City School District, Springfield, Ohio.

Data was collected in three phases. Phase one consisted of a questionnaire distributed district-wide to special educators and related health services personnel. Phase two consisted of focus groups, one with special educators and one with related health services personnel. Phase three data collection consisted of a final focus group combing both special educators and related health service personnel.

Findings were that special educators and related service personnel participating in this study agreed, in general, on the definition of interdisciplinary collaboration. Participants in this study mutually agreed on the definition of collaboration, they perceived a lack of support and understanding of collaboration on the part of administrators which they identified as a barrier. A third area of general agreement involved the constraints of time. Participants reported that finding the time to develop collaborations was a serious problem. A unique opportunity for improved collaboration when serving students with moderate and severe disabilities at the middle and high school levels was identified. Both special educators and related health services personnel identified transition to be an opportunity. Despite the existence of several barriers to the development and implementation of effective collaborations, the value of collaboration was recognized by participants. 


\section{Dedication}

This dissertation is dedicated in memory of my parents:

Ruth P. Brannan

$\&$

Thomas L. Brannan, Jr.

who laid my foundation for understanding community and collaboration. 


\section{Acknowledgements}

To my committee: Barbara L. Ludlow, Ed.D.who served not only as chair, but as my mentor, colleague, and friend; Elizabeth A. Dooley, Ed.D., Samuel F. Stack, Ph.D., Sherry Wood-Shuman, Ed.D., and William Reger-Nash, Ed.D. for their support and perseverance over the years.

To my fellow doctoral students and in particular: Steve Pavlovic, John Foshay, Holly Pae, Billie Friedland, Jim Tackas, and Kalie Kossar who have shared their insights as well as a few dinners and kept me going.

To the administrative assistants: Wilma Phillips, Sherry Bunner, Donna Stagg, and Kari Hudson whose professional knowledge have gotten me thorough many tight spots, and whose friendships and supports I could not have gone without.

To my former colleagues at the Easter Seal Rehabilitation Center, Wheeling, WV and Marshall County Schools, Marshall County, WV and to my current colleagues in the Education Department at Wittenberg University, Springfield, $\mathrm{OH}$ who have been true collaborators.

To my friends for their support and encouragement and in particular: Cathy Irish, Kara Novel-Groves, Mary Beth Mihalick, and Marilyn Dague who never had any doubts even though I had plenty. To Mike Duff for his support and encouragement, as well as for expanding my outlook on technology and putting out the fires when I got stuck.

To my family: Tom, Janet, and T.W. in Alaska, Rick, Debbie, Scott, and Ryan in Ohio, and Dave in Florida who supported me from afar, but who were near to me at all times.

And finally, to the one who has supported me all along, I acknowledge you with this analogy- You were to the completion of this dissertation and degree as you are to my life: instrumental. 
Table of Contents

$\begin{array}{ll}\text { Abstract } & \text { ii }\end{array}$

Dedication $\quad$ iii

Acknowledgements $\quad$ iv

$\begin{array}{ll}\text { List of Tables } & 121\end{array}$

$\begin{array}{ll}\text { List of Figures } & 122\end{array}$

Chapters

I- $\quad$ Statement of the Problem 1

$\begin{array}{lll}\text { II- } & \text { Review of the Literature } & 16\end{array}$

$\begin{array}{ll}\text { III- } \quad \text { Design of the Study } & 29\end{array}$

IV- Results 45

$\begin{array}{ll}\text { V- Discussion } & 75\end{array}$

$\begin{array}{ll}\text { References } & 89\end{array}$

Appendices

$\begin{array}{lr}\text { Appendix A } & 98\end{array}$

$\begin{array}{ll}\text { Appendix B } & 100\end{array}$

$\begin{array}{ll}\text { Appendix C } & 105\end{array}$

$\begin{array}{lr}\text { Appendix D } & 106\end{array}$

$\begin{array}{ll}\text { Appendix E } & 108\end{array}$

$\begin{array}{lr}\text { Appendix F } & 115\end{array}$ 


\section{Chapter I \\ Statement of the Problem}

\section{Introduction}

In order to serve individuals with moderate and severe disabilities in accordance with federal legislation and current best practices, it is important that education and related health services professionals work together collaboratively. If these collaborative efforts are to bear fruit, it is imperative that those involved have a mutual understanding of their respective roles and responsibilities as well as the beliefs and expectations of the other collaborating team members. If genuine and effective collaborations are not achieved, then the desired outcomes for these students may not be accomplished. In addition, the working relationships among the professionals themselves can be significantly impaired.

Students who have moderate and severe disabilities are entitled to the provision of education and related services through the Individuals with Disabilities Education Act (IDEA). The Association for Persons with Severe Handicaps (TASH), the American Occupational Therapy Association (AOTA), the American Physical Therapy Association (APTA), and the American Speech-Language-Hearing Association (ASHA) all have issued statements addressing the role of the related health professional as one that is to work jointly with educators and students' families for the provision of services that support individuals with severe and multiple disabilities to participate in home, school and community settings (Rainforth, York, \& Macdonald, 1992). Current best practice encourages and emphasizes the integration of education and therapy and also recommends the provision of such services in the 
most naturally occurring setting (least restrictive environment) for the best acquisition and generalization of skills. This ecological model of education (Brown et al., 1979) has been well defined and supported (Orelove \& Sobsey, 1991; Rainforth, York, Macdonald, 1992; Snell, 1993).

The value of achieving strong interdisciplinary collaborative relationships became increasingly evident to me both during my tenure as a preschool special needs teacher at an Easter Seal Rehabilitation Center and as a teacher of high-schoolaged students with severe and multiple disabilities in a public school system. At times, I observed and or participated in true collaborative relationships among teachers and therapists that resulted in positive outcomes for students and creative solutions for mutual problems. For my colleagues and for me, such productive interactions reinforced and informed our future collaborative efforts, resulting in fewer perceived barriers and a heightened awareness of the potential opportunities for improving services for each student and family, as well as enhancing our professional growth and development. In this manner, a “win, win” situation was attained for all involved. At other times, however, failure at one link in the collaborative chain led to less than optimal results for a student, and negatively influenced our behaviors, performances and expectations. This often created additional barriers and missed opportunities for all involved.

The topic of collaboration continues to be of high interest to me. This is true because I am still involved in collaborative endeavors myself, since, as a college instructor, I must teach students how to be effective collaborators for their future roles as general and special educators. The topic of collaboration has become a personal 
academic research interest. Consequently, I have already conducted research on the topic of collaboration in two preliminary qualitative studies.

In the first of these studies, I explored how the term "collaboration” was defined and how collaboration was taught within the academic programs of the following professional disciplines: speech/language pathology, nursing, physical therapy, occupational therapy, social work, educational administration, elementary and secondary education, and special education. This was accomplished by conducting personal structured interviews with the departmental chairperson in each discipline. In the second study, I examined the manner in which the values and skills of collaboration were incorporated and demonstrated in a high school special education program. This program included special education teachers (Specific Learning Disabilities, Behavior Disorders/Severe Emotional Disturbance, Mental Retardation, Severe and Multiple Disabilities), the transition coordinator, job training coaches, an occupational therapist, certified occupational therapy assistants, a physical therapist, a speech and language pathologist, a specialist in vision impairments, a school nurse, and general education teachers. Results and conclusions from these two studies proved to be informative and raised some additional concerns. These are briefly summarized below.

My first general conclusion was that no formal definition of the term collaboration could be identified by any of the participants, regardless of discipline. Nevertheless, all were able to define the term informally within the context of their own field and its practice. I feel the lack of formal definitions, or even a common informal definition, may contribute to different and, often changing expectations of 
the practices and outcomes associated with collaboration among the disciplines examined. Many other researchers have found this to be true and confirm that these differing definitions often lead to confusion when serving students with disabilities (Briggs, 1997; Fleming \& Monda-Amaya, 2001; Friend \& Cook, 2003; Johnson \& Johnson, 1991; Thomas, Correa, \& Morsink, 1995; Walther-Thomas, Korinek, \& McLaughlin, 1999). This confusion of defining collaboration and using various other words to impart the meaning of collaboration has also occurred in the field of business (Fleming \& Monda-Amaya, 2001).

My second general conclusion was that broad agreement existed among all professionals and other personnel, regardless of discipline, that collaboration among practitioners of the various disciplines was highly desirable. Nevertheless, every person I interviewed expressed concern that some individuals within their own field did not, or would not, readily collaborate with others. The recognition of the importance of teaming in serving individuals with disabilities was recognized as early as 1962 in an article by Beck that addressed the advantages of a multi-purpose clinic for individuals who had mental retardation (Beck, 1962). This notion has continued to be developed and supported in the professional literature (Allen, Holm, \& Schiefelbusch, 1978; Golin \& Ducanis, 1981; Ogletree, Bull, Drew, \& Lunnen, 2001).

My third major conclusion was that there is a general recognition that collaboration between professionals is especially desirable during the periods of assessment, planning, and program delivery. However, only some professionals from certain disciplines envision parents and families as possible collaborators. This 
omission was further highlighted by the fact that the most often cited key components of collaboration were skills associated with professional interactions and consultation, as opposed to those needed for family involvement and partnership. In contradiction to this finding, IDEA requires the active participation of parents/guardians and their involvement has been, and continues to be, a hallmark of best practice.

Finally, it soon became apparent in my studies that the means by which collaborative skills were acquired differed greatly between medical and educational personnel. The nursing, occupational therapy, and physical therapy professionals received formal training in the conduct of a multidisciplinary team approach. On the other hand, educators and administrators received little or no formal training, but indicated that working within a collaborative atmosphere was informally implied and recognized as best practice. In articles by Lewis et al. (1998) and Stayton, Whittaker, Jones, \& Kersting (2001), the authors identify the need for training in interdisciplinary practice and collaboration across the disciplines of education and medicine. They also note the differing approaches to the development of collaborative skills and multidisciplinary teaming. Others have found that when individuals are taught interdisciplinary collaboration in preservice programs, they are more likely to apply the practice to their own careers (Winton \& Merlin, 1997).

From the results of these studies, I derived several considerations for improvements in the areas of education and training of professionals and paraprofessionals. The specific ideas were as follows: 1) individuals with special needs are best served by collaborative efforts among their team members and service agencies; therefore, a common understanding of collaboration is both relevant and 
imperative to best practice, 2) professionals should be able to identify and compare how collaboration is defined and practiced across various disciplines that typically serve individuals and families with special needs; and, 3) professionals should also gain an understanding of how educational and medical models differ in their view and practice of collaboration. The findings of these studies have guided me in formulating the problem statement below.

\section{Problem Statement}

Federal legislation through the Individuals with Disabilities Education Act (IDEA) mandates a free appropriate public education that takes place in the least restrictive environment. For students with special needs, this includes both educational and therapeutic services. Thus, special educators and related health service providers must collaborate in order to provide services to these students. This is especially important for those students who have moderate and severe disabilities. Because of the multiplicity and the complexity of their needs, such students typically are served by more personnel and they often require integration of education and therapy to promote development and learning. In the absence of effective collaboration among service providers, there is the potential for needless redundancy in individual programming and the more serious problem that an essential component of service for an individual may be omitted. The former may result in the inefficient use of personnel time and district resources, and the latter may lead directly to limiting the progress of the individual student. Furthermore, another consequence of ineffective team collaboration can be observed in the personal interactions among the collaborators. Animosities and "turfism" may develop and the resulting poor work 
environment may negatively impact not only student outcomes but also job satisfaction for the professionals themselves. Nevertheless, I found no studies that investigated the collaboration among interdisciplinary professionals serving students with moderate and severe disabilities at the middle and high school grade levels. The few studies that do exist address this issue only with young children in early intervention and elementary school programs.

Purpose of the Study

The purpose of this study was to explore the perception of specific barriers and opportunities for collaboration as identified by special education teachers and related health service providers when serving students with moderate and severe disabilities at the middle and high school level. The study was conducted using participants drawn from the staff of the Springfield City School District in Springfield, Ohio. This study consisted of three parts in sequence. Initially, I sent a Likert scale questionnaire to all special education teachers and related health service personnel in order to elicit their understanding of collaboration as individuals. This information was used to inform and develop questions for several focus groups. I then conducted two focus groups, consisting of the following: a) special education teachers serving students with moderate and severe disabilities at the middle and high school levels, interviewed alone and b) related health service providers serving students with moderate and severe disabilities at the middle and high school levels, interviewed alone. Lastly, I brought together participants from both of these groups to comprise the final focus group. These focus groups were utilized to further explore the 
perceived barriers and opportunities for collaboration when serving students with moderate and severe disabilities at the middle and high school levels.

\section{Guiding Research Questions}

The specific questions addressed in this study were the following:

1. Are there barriers and opportunities for collaboration that are unique to the middle and high school settings?

2. What are the currently perceived barriers to collaboration between special education teachers and related health service personnel when serving students with moderate and severe disabilities at the middle and high school levels?

3. What are the currently perceived opportunities for collaboration between special education teachers and related health service personnel when serving students with moderate and severe disabilities at the middle and high school levels?

4. Can areas of agreement be identified related to the process of collaboration between special education teachers and related health service personnel when serving students with moderate and severe disabilities at the middle and high school levels?

5. Can areas of disagreement be identified related to the process of collaboration between special education teachers and related health service personnel when 
serving students with moderate and severe disabilities at the middle and high school levels?

6. What specific suggestions can be made to promote more effective collaboration when serving students with moderate and severe disabilities at the middle and high school levels?

Definition of Terms

Collaboration

"a style for direct interaction between at least two coequal parties voluntarily engaged in shared decision making as they work toward a common goal” (Friend \& Cook 2003, p.5).

Focus group

a qualitative research method of data collection that utilizes group interview and discussion of a focal topic.

High school grades $9,10,11$, and 12 as outlined by the Ohio Department of Education (ODE).

Middle school grades 6,7 , and 8 as outlined by ODE. Moderate disabilities students whose IQ level is between 55-35, this category is covered under the term "cognitive disabilities” (mental retardation) as defined by ODE as: means significantly subaverage 
general intellectual functioning, existing concurrently with deficits in adaptive behavior and manifested during the developmental period, that adversely affects a child's educational performance.

Related health service personnel

ODE defines "related services" as transportation and such developmental, corrective, and other supportive services as are identified on the child's IEP and required to assist a child with a disability to benefit from special education. Related services may include, but are not limited to the following: attendant services, audiology, counseling service, guide services, interpreter services, medical services, occupational therapy, occupational therapy assistant services, orientation and mobility services, parent counseling and training, physical therapy, reader services, recreation, rehabilitation counseling, school health services, school nursing services, social work services, speechlanguage pathology services. For the purposes of this study, the following service providers: 
physical and occupational therapists, speech and language pathologist, and school nurses.

Severe and multiple disabilities

Special educators means concomitant impairments (such as

mental retardation-blindness, mental retardation-orthopedic impairment, etc.), the combination of which causes such severe education needs that they cannot be accommodated in special education programs solely for one of the impairments. The term does not include deaf-blindness. (ODE). teachers employed to provide educational services to students identified as having moderate and severe and multiple disabilities.

\section{Significance of the Study}

My expectations were that the results of this study would contribute significantly to both the current body of literature and professional practice when serving individuals with disabilities in the following ways:

1) This study would identify practices that facilitate collaborative efforts that foster and promote services for students with moderate and severe disabilities in middle and high school settings. 
2) This study would generate and provide suggestions for training strategies to be incorporated in personnel preparation programs for special educators, as well as for related health service personnel.

3) This study would give rise to recommendations for policy and practice in state and local education agencies to support professionals in collaboration through staff development activities and administrative support and oversight.

4) This study would contribute to the limited literature available on the topic of collaboration, especially as it relates to the middle and high school levels for students with severe and multiple disabilities.

5) This study would increase the awareness of the study participants with respect to their own interdisciplinary collaborative practice.

\section{Limitations of this study}

Given the design of the study and subject population, I recognized that the limitations listed below must be considered in interpreting the results and formulating conclusions.

\section{Generalization of findings and conclusions.}

The aim of qualitative research is not the generalization of results to a larger population, but rather the acquisition of an in-depth understanding derived from evidence found in separate cases over time (McMillan \& Schumaker, 1993). 
However, some generalization is possible through the process of extracting common themes from the qualitative data analyses across multiple studies (Miles \& Huberman, 1994, Creswell, 2002). Since this study has not yet been replicated, the findings are bound to the context in which they were collected and interpreted. Nevertheless, this study may prove useful to other interested investigators and practitioners and enable them to extend their own investigations and improve their practice.

\section{Potential imbalanced participation.}

In designing this study, I attempted to establish some degree of balance within the participants. The first manner in which I approached this was to mail a questionnaire to all special educators and therapists working with students identified as meeting the requirements for special education services in the Springfield (Ohio) City School District. As expected, the response rate was less than one-hundred percent. Sixty-five percent of the surveys were returned. These completed questionnaires were analyzed and the results were used to develop topics for examination by the more narrowly constructed focus groups. Only those special educators and related health services personnel working with students identified as having moderate and severe disabilities at the middle and high school levels were invited to participate in the focus groups. Thus, no personnel at the elementary level were included.

The outcomes of any focus group depends on individual variation in the ability and/or willingness of group members to express themselves. It was my responsibility as the principal investigator to recognize limited participation and to 
provide a conducive environment and personal encouragement for equal participation. As the group moderator, I attempted to foster participation in the following ways:

a) As the moderator I was mentally alert and present throughout the discussion.

b) I created a warm and friendly environment for the participants by making small talk prior to the session while purposely avoiding the key issues to be discussed later.

c) The focus group room was easy to locate, relatively free from distractions and had chairs such that the participants faced each other.

d) As moderator, I was concerned with the direction of the discussion, promoting the flow of the discussion, and taking only minimal notes in order to identify future questions that needed to be asked. I employed two essential techniques including the "Five Second Pause” and "the Probe.” The Pause often prompted addition points of view or agreement especially when accompanied with eye contact from the moderator. The Probe consisted of a request for additional information (e.g., "Could you give me an example of what you mean?”; "Please describe what you mean.”)

e) The focus group interview was recorded on audio tape and video tape and written notes were taken by an assistant moderator, allowing me to remain engaged and connected to the group conversation.

f) As moderator, I promoted the creation of a thoughtful, permissive climate for the unhindered sharing of information among participants. This was accomplished, in part, by my setting the tone for the discussion. I established 
Collaboration 15

and maintained positive rapport with all participants, permitted time for response and reflection, and monitored body language among participants. 


\section{Chapter II}

\section{Review of the Literature}

In this review of the literature, I will examine the history of collaboration among special education teachers and related services personnel in the provision of special education programming for students under the Individuals with Disabilities Education Act (IDEA). The concept and process of collaboration, as it relates to the processes of consultation, teaming, co-teaching and service delivery will be addressed and defined for the purpose of this study. Finally, the literature review will identify the beneficiaries of collaboration and summarize current practices and strategies for personnel preparation and professional development related to the process of collaboration.

\section{History of Collaboration in Special Education}

The concept of collaborative teaming when serving individuals with disabilities and special learning needs is not a new phenomenon. In an early article by Whitehouse (1951), the notion of teaming was presented with claims that it improved services and allowed them to be provided in a more professional manner for children with special needs. The first formal legal mandate for teaming and collaboration arose in 1975 with the passage of Public Law 94-142, the Education of All Handicapped Children Act. This law served as an impetus for professionals of differing disciplines to work together collaboratively. This statement of collaboration is tied to the law's multi-factored evaluation process. The law specifically stated in section 121a532(e) that, "the evaluation is made by a multidisciplinary team or group of persons, 
including at least one teacher, or other specialist, with knowledge in the area of suspected disability." This initial legislation moved the primary decision-making role from the school psychologist to a multi-disciplinary team that included the school psychologist, but also involved teachers, school administrators, physicians, nurses, social workers, counselors and parents (Kaiser \& Woodman, 1985).

In 1986, Public Law 99-457, the Education of the Handicapped Act Amendments, strengthened the call for collaboration among service providers, especially for those involved with young children (birth through age 2) with developmental disabilities or delays and those young children considered at risk for later problems. Part $\mathrm{H}$ of the legislation required the development of statewide, coordinated, comprehensive, multidisciplinary, interagency programming (Siders, Riall, Bennett, \& Judd, 1987). This legislation helped move the concept of collaboration beyond the local school district and its employees or contracted providers to the broader scope of interagency coordination in the provision of services to children with special needs.

In 1990, Public Law 94-142 was amended by Public Law 101-476 and renamed as the Individuals with Disabilities Education Act (IDEA). This revision placed more emphasis on collaborative teaming and stipulated that increased collaboration among special educators, classroom teachers, and related services personnel must occur. It also addressed the need for interagency collaboration. Rothestein (1995) summarizes this provision:

Many of the related services required by the IDEA are services that were provided by other agencies before passage of IDEA. Services such as residential placements for children who are severe emotionally disturbed or certain kinds of therapy may have been forthcoming from state agencies such 
as departments of health and human services and departments of welfare. Other health-related services were provided or at least paid for by family health insurance agencies. The IDEA makes the state education agency the primary supervisor for the provision of related services that are required for the child to benefit from special education. State educational agencies must have the general supervisory role for coordinating service delivery by other agencies, but the IDEA provides no real means to mandate that other agencies provide certain services. (p. 154).

Coben, Thomas, Sattler, and Morsink (1997) noted that each successive version or revision of the law called for the involvement of numerous individuals from various professional disciplines, as well as the students and their families, for the purpose of identification, program design, and delivery of services for children with disabilities. These legal mandates necessitated the development and implementation of collaborative efforts, including interdisciplinary teams serving students with educational as well as health and medical needs.

Fishbaugh (1997) provides a final note on the legal precedents for collaboration in special education and disability services across the life span. In her book, Models of Collaboration, she cites Section 504 of the Rehabilitation Act of 1973 as civil legislation that can be applied to support students who may not meet the criteria for services under IDEA, but may need reasonable accommodations if they have a physical and/or mental disability that interferes with a major life activity. Students in this category may include those with chronic illness, diabetes, AIDS or even pregnancy, all of which may necessitate collaborative efforts to implement the appropriate accommodations to suit the individual's educational needs.

\section{Collaboration Conceptualized and Defined}

Any exploration of collaboration would not be complete without presenting how collaboration has been applied and defined by professionals in the areas of 
special education and disability services. Friend and Cook (2003) suggest that there has been much discussion of and writing about collaboration, but that few clear formal definitions have been set forth. In their book, Interactions: Collaboration Skills for School Professionals, the authors further state that "the term collaboration often is carelessly used and occasionally misapplied” (2003, p. 4). They note that some authors have described the benefits of collaboration without defining it, and others have treated collaboration as a synonym for other concepts, such as teaming or consultation. Overall, they believe that most authors tend to define collaboration as a process of working together for mutual benefit.

Numerous and varied definitions have been presented and utilized in books, journal articles and research studies. I offer a few examples of the varying definitions below to provide insight into the conceptualization of collaboration. These definitions have aided me in defining the term for the purpose of the proposed study.

Collaborative consultation- an interactive process that enables people with diverse expertise to generate creative solutions to mutually defined problems. The outcome is enhanced, altered, and produces solutions that are different from those that the individual team members would produce independently. The major outcome of collaborative consultation is to provide comprehensive and effective programs for students with special needs within the most appropriate context, thereby enabling them to achieve maximum constructive interaction with their non-handicapped peers (Idol, Paolucci-Whitcomb \& Nevin, 1994, p.1).

Collaboration means working together for a common end. As educators and human service professionals collaborate, they should do so with a knowledge of different models for collaborating, and recognition of the different purposes for their collaborative practice (Fishbaugh, 1997, p.4).

Collaboration is a style of professional interaction between and among professionals, parents and families, and, where appropriate, students themselves to share information, to engage in collaborative decision making, and to develop effective interventions for a commonly agreed upon goal that is in the best interests of the student (Mostert, 1998, p.16). 
Collaboration is a style for direct interaction between at least two coequal parties voluntarily engaged in shared decision making as they work toward a common goal (Friend \& Cook, 2003, p. 5).

It is the last of these definitions that I have chosen for use in the proposed study. Friend and Cook (2003) also describe six elements or defining characteristics related to the process of collaboration. These defining characteristics are:

1. "Collaboration is voluntary; it is not possible to force people to use a particular style in their interactions with others” (p. 6).

2. “Collaboration requires parity among participants”(p. 7).

3. “Collaboration is based on mutual goals" (p. 8).

4. “Collaborating depends on shared responsibility for participation and decision making” (p. 8).

5. “Individuals who collaborate share resources” (p. 10).

6. “Individuals who collaborate share accountability for outcomes” (p. 11).

\section{Collaboration among Special Educators and Related Services Personnel}

IDEA identifies special education personnel as those qualified to provide educational services as outlined by individual state licensure guidelines and related service personnel as those individuals who provide supportive services which allow the student with identified disabilities and other special learning needs to benefit from education. Collaborative practices among teachers and related service personnel, such as physical and occupational therapists, speech/language pathologists, medical and counseling/social services have been longstanding and well documented for individuals with disabilities (Idol, 1983; Orelove \& Sobsey, 1991; Rainforth, York, \& Macdonald, 1992). Most recently, collaboration has been a predominant feature of 
services for young children from birth to three and for individuals with severe and multiple disabilities of all ages. This is related to the intensity and multiplicity of needs for young children in the early stages of development or older individuals with multiple physical, medical and/or educational needs. In both of these areas, various teaming models have been established with interdisciplinary and transdisciplinary teaming being explicitly defined and associated with special education and disability services (Friend \& Cook 2003; Orelove \& Sobsey, 1987, 1991; Rainforth, York, \& Macdonald, 1992).

Although allied health professions have provided services to children and adults with disabilities for many years, the presence of medical and therapy services in educational settings has grown over the past twenty-five years. Prior to the passage of Public Law 94-142 in 1975, therapy services were most commonly provided in medical facilities and residential living facilities (McAfee, 1987). Since then these services have moved into the school environment. Irving Independent School District vs. Tatro (1984) was the landmark case in which the U.S. Supreme Court ordered schools to provide appropriate health services if a student in special education required a health procedure during the school day (Rapport, 1996). The provision of such medical and therapeutic services has continually increased in the school setting with each revision of the law. As young children who were served through early intervention programs that used interdisciplinary and transdisciplinary service delivery models reach school age and transitioned into the school setting, their parents brought with them an expectation of well coordinated team services in the school program as well. Over time, there has also been an increase in the number of 
students who require medical procedures during the school day. Such procedures include tube feedings, ventilator and oxygen management, catherization, and the administration of medication (Heller, Fredrick, Best, Dykes \& Tucker-Cohen, 2000; Heller, Fredricks, \& Rithmire, 1997; Lehr, 1990; Mulligan-Ault, Guess, Struth, \& Thompson, 1988). As students with severe and multiple disabilities are increasingly integrated and included into education programs, the need for collaboration between the education and allied health professions has become more apparent and necessary (Hunt, Hirose-Hatae, Maier, \& Goetz, 2001).

In both the educational and medical literature, differences in approaching collaboration exist and have been reported (Dettmer, Thurston \& Dyck, 2002; Downing, 2002; Howard, Williams, Port \& Lepper, 2001; Purvis \& Whelan, 1992). The issues raised by these studies have to do with differences in professional preparation and orientation, the limited amount of time spent in particular settings, the size of the therapy caseload, and whether the related service personnel are hired directly by the district or contracted through an agency. Dettmer, Thurston, and Dyck (2002) discuss how these differences result in related service providers feeling as if they are working from a very different standpoint from the educators with whom they are expected to collaborate. Additionally, such differing views may lead to misunderstandings, miscommunications, and potential or outright conflict. The preparation of individuals within the varying fields of allied health services, including physicians, nurses, physical therapists, occupational therapists, and speech/language pathologists, tends to approach collaboration from the medical model which can be considered as a top-down approach, viewing the medical professional as the expert 
(McAfee, 1987). In the past, this has led to issues of "turfism" among related service personnel from differing therapeutic areas and between related service personnel and educators. This hierarchical medical model unfortunately often envisions and places educational personnel on a lower rung (Bateman, 1995). This can result in limited or constrained communication among professionals, incompatible goals and activities in programming, and an overall lack of coordinated service delivery. To address these concerns, new models are now emerging for training both educators and service providers in skills related to collaboration (Dettmer, Thurston, \& Dyck, 2002; McAfee, 1987; Rainforth, York, \& Macdonald, 1992). With the growing recognition of the importance of collaboration and the problems posed by differing perspectives from the medical and educational viewpoints, this issue is being addressed currently not only at the graduate and inservice level but also at the undergraduate and preservice level of preparation (Gable, Young \& Henderickson, 1987; Gable, Hendrickson \& Rogan, 1996). The issues of interdisciplinary training and personnel preparation have received most emphasis in the area of early intervention (Bailey, Simeonsson, \& Yoder, 1990; Cochrane, Farley, \& Wilhelm, 1990; Dinnebeil, Hale, \& Rule, 1999; Heston, et al. 1998; Humphry, \& Link, 1990; Winton, 1995). Training programs include topics such as effective communication, scheduling and creating time for collaboration to occur, and working with paraprofessionals and families. Despite the recognition of the importance of preparing multiple disciplines for collaboration, in the area of severe and multiple disabilities this topic has been somewhat/relatively neglected. As a result, little is known about what opportunities for and barriers to collaboration are 
perceived by practitioners currently out in the field providing daily services to these students.

\section{Research on Collaboration}

In the discipline of special education, research on collaboration has primarily focused on students with mild to moderate disabilities being served in inclusive classrooms and in the area of early intervention for young children from birth through age five. The studies in early intervention have investigated collaborative practices with parents as well as interagency collaboration as it relates to improved service provision. The research studies in special education for school-aged students have focused on co-teaching practices between general and special educators, effectiveness of school-based intervention teams (Aksamit \& Rankin, 1993; Bahr, Whitten, Dieker, Kocarek, \& Manson (1999); Sindelar, Griffin, Smith, \& Wantanabe (1992); Whitten \& Dieker (1995) as well as student peer collaboration within the classroom (Van Meter \& Stevens, 2000). Overall, these studies found that the special educator typically assumes the primary role of service provider for the student with special needs. When co-teaching in a general education classroom, it was found that initially special education teachers and the general education teachers viewed their roles as discrete, but as the team worked together this separation of roles was lessened. It was also reported that the special educator and the administrator serve as the primary communicators to the family when serving students through collaborative teams.

As for students with severe and multiple disabilities, one small study investigated how collaborative teaming could support three students with severe disabilities and three students who were considered at risk academically into general 
education classrooms (Hunt, Soto, Maier, Doering, 2003). It should be noted, however, that this study only used collaboration teams that consisted of educators and parents. Another qualitative study, carried out in one California school district, investigated teachers' perceptions of collaborative teaching and their role in efforts to include students with severe disabilities in elementary general education classrooms (Wood, 1998). Again, it should be noted that this study only used general and special educators and key administrators involved in educational service provision and did not include therapists. Two final studies were completed by Snell and Janney. Their initial research investigated how students with moderate and severe disabilities were included in elementary classrooms (Janney \& Snell, 1997). This was an ethnographic study that looked at the manner in which general and special educators included such students. Their findings suggested that all teachers shared similar goals and preferred written plans or at least verbal agreements as to how the inclusive process would occur and what modification would be needed. A follow-up study was also ethnographic in nature and investigated how teachers planned for children requiring extensive supports and services (Snell \& Janney, 2000). In this study, the researchers' primary focus was to consider how decisions were made about practices and programming (Snell \& Janney, 2000). Three students enrolled in kindergarten and first grade classrooms were selected as case studies for this research. The researchers found that child focused concerns from the inclusive classroom fell into three categories: 1) student goals and abilities, 2) participation, and 3) classroom community. When the researchers considered how the team approached problemsolving, they noted that decisions were made based on the level of immediacy 
required. Snell and Janney (2000) stated that by using this method of problemsolving the general education teachers often did not engage in brainstorming, and that it reduced the overall participation for all team members. They concluded that when serving students with moderate and severe needs in inclusive classrooms the special education teacher's role requires a focus on both the student and the team even though logistical barriers exist that do not allow the special educator to be ever present in the inclusive classroom. They further state that "the special education teacher needed to discriminate the planning styles and instructional focus of classroom teachers and other team members, to assess team dynamics, and to adjust her consultative interactions accordingly when tutoring staff to work as a team to resolve unconventional child-centered challenges” (2000, p.16).

Unfortunately, the area of interdisciplinary collaboration among service providers (allied health professionals and general and special educators) has been significantly neglected across early intervention, special education, and health care. This gap in the research is most evident in special education for students with moderate and severe disabilities beyond the elementary school years. Beneficiaries of the Collaborative Process

The obvious beneficiary of a collaborative approach to the provision of services in special education and disability services is the student, followed by parents, siblings, and other family members. Less obvious, but also important, are the benefits derived by the collaborators themselves and those derived by administrators, programs, and society as a whole. These benefits have been noted and reported by many (Dettmer, Thurston \& Dyck 2002; Friend \& Cook, 2000, 2003; Fishbaugh, 
1997; Idol, 2002; Mostert, 1998; Thomas, Correa \& Morsink, 2001). The current literature has presented several major themes as benefits of collaboration: creative solutions to issues and problems; optimal use of time; more opportunities to learn from others; improved practices and accountability; enhanced resources; increased knowledge and skills; and lastly, school and systems reform. Although the detriments noted have been few in number, these have included scheduling problems; increased personnel cost, time subtracted from the provision of services; and reduced caseload size (Dettmer, Thurston \& Dyck 2002; Fishbaugh, 1997; Thomas, Correa \& Morsink, 2001).

In the current millennium, collaboration among the fields of medicine, public health, social services and education will continue to generate new approaches for professionals and students, enhance the development of programming, provide better individual and family services, and advocate for improved services and health care legislation. Collaboration will forge new roads of access for the students and families served, as well as for the professionals involved in the process. These include improved programming and congruent student outcomes, solid transitioning, and increased professional contact. The study described in the next section was designed to obtain a snapshot of the current state and practice of collaboration within a single school district serving students with moderate and severe disabilities at the middle and high school levels. In addition, this study was conducted to identify current perceived barriers to better collaboration, as well as opportunities that exist but have not yet been pursued. It was my hope that this information would contribute to an area for which there is little data in the current literature. It was also my hope that the 
Collaboration 28

results would contribute to the further development of informed best practice in this area. 


\section{Chapter III}

Design of the Study

\section{Introduction}

In this chapter is discussed the quantitative and qualitative methods used to examine the following guiding research questions:

1. Are there barriers and opportunities for collaboration that are unique to the middle and high school settings?

2. What are the currently perceived barriers to collaboration between special education teachers and related health service personnel when serving students with moderate and severe disabilities at the middle and high school levels?

3. What are the currently perceived opportunities for collaboration between special education teachers and related health service personnel when serving students with moderate and severe disabilities at the middle and high school levels?

4. Can areas of agreement be identified related to the process of collaboration between special education teachers and related health service personnel when serving students with moderate and severe disabilities at the middle and high school levels?

5. Can areas of disagreement be identified related to the process of collaboration between special education teachers and related health service personnel when serving students with moderate and severe disabilities at the middle and high school levels? 
6. What specific suggestions can be made to promote more effective collaboration when serving students with moderate and severe disabilities at the middle and high school levels?

Initially, the responses to a questionnaire were analyzed quantitatively. The results of this questionnaire were used to formulate probing questions to be use in a series of focus groups. Data derived from the focus were analyzed qualitatively.

\section{Quantitative Analyses: Differences Among the Groups}

The quantitative results of the survey were analyzed using non parametric statistics. Specifically the Kruskal-Wallis test was used and a $p$ value of $<.05$ was taken to be significant. In contrast to the more familiar quantitative approach to data collection and analysis, qualitative research involves broad and open-ended questions that allow participants to share their views concerning the topic of study (Creswell, 2002). Creswell states that the outcomes of a qualitative study can be described as descriptive (i.e., What happened?), interpretive (i.e., To what do/did the participants attribute what happened?), and process oriented (i.e., What happened over time?). The qualitative approach was selected in order to keep the direction of the study open and informed by the participants. In qualitative research, the interpretation emerges from analyses of the detailed stories, quotes, and documents provided by the participants.

Qualitative research can also be defined by its data collection strategies. The three main data collection strategies related to qualitative investigation are interview, observation, and document review (Grady, 1998). Data analyses in qualitative 
research involve the process of inquiry known as analytic induction. Patton (1990) defines inductive analysis as "the immersion in the details and specifics of the data to discover important categories, dimensions, and interrelationships; by exploring genuinely open questions rather than testing theoretically derived (deductive) hypotheses” (p. 40). The development of the theory by this process follows the collection of qualitative data, the formulation of hypotheses based on the data, and testing of the hypotheses against the data. The theory developed in this manner is called grounded theory, because it arises out of and is directly relevant to the particular setting or topic under study (Frankfort-Nachmias \& Nachmias, 1996). Qualitative inquiry and grounded theory methodology include ten classic perspectives that have arisen from various disciplines including anthropology, philosophy, psychology, sociology, natural sciences, and even theoretical physics. From among these, I have chosen the perspective of phenomenology which has its roots in philosophy. Phenomenology, as a philosophical tradition, was introduced by Edmond H. Husserl (1859-1938). Early in the last century, Husserl (1913) described phenomenology as the study of how people describe things and experience them. His philosophical assumption was that "we can only know what we experience” by attending to perceptions and meanings that awaken our conscience awareness. Thus, the development of understanding comes from sensory experience of phenomena followed by a description, explanation and interpretation of the sensory experience. Descriptions of experience and interpretations are intertwined such that they often become one. From a phenomenological perspective, the focus becomes how we put together the phenomena that we experience in such a way that we make sense of the 
world and in so doing develop a world view. Phenomenology, as a major philosophical and social science perspective informing inquiry, has been influenced by the works of many authors (Patton, 1990).

Patton (1990) suggested that there are two implications of the phenomenological perspectives that are often confused. The first implication is that it is important to know what people experience and how they interpret the world. This is the focus of phenomenological inquiry. The second implication deals with methodology and the importance of participant observation. It might be assumed that the only way for us to "really know" what another person experiences is to experience it for oneself. Patton (1990) states that the confusion can be resolved with the realization that the phenomenological perspective can mean either or both of the following: (1) a focus on what people experience and how they interpret the world (in which case, interviews can be used and actual experience of the phenomenon is not required), or (2) a methodological mandate to actually experience the phenomenon under investigation (in which case, participant observation is required). I have chosen the first of these perspectives for this study.

Patton (1990) also describes one final dimension that defines a phenomenological approach, that is, the assumption that "there is an essence or essences to shared experience” (p. 70). These essences are the core meanings derived and understood through a commonly experienced phenomenon. Subsequent to the collection of the qualitative data, the experiences of different people were coded, analyzed and compared, and from this process the essence(s) of the phenomenon emerged. In Patton’s words, “The assumption of essence, like the ethnographer’s 
assumption that culture exist and is important, becomes the defining characteristic of a purely phenomenological study” (p. 70).

Since this study focused on the shared experience of collaborators in the educational setting who serve students with moderate and severe disabilities at the middle and high school levels, I determined that the qualitative research approach and phenomenological perspective were appropriate. As described in detail below, I used a series of focus groups to allow the participants to explore and investigate their shared experiences related to the barriers and opportunities for collaboration in this setting. Subsequent coding and analysis of the data allowed me to determine the emerging themes related to the shared experience. These themes can then inform best practice by being used to reinforce the elements that currently work, as well as to identify persistent barriers and potential opportunities for improved collaboration.

\section{Design and Implementation}

The design of this study combined a simple quantitative survey measure with an exploratory, qualitative inquiry using open-ended focus group interviews (see figure 1). A focus group interview is an interview with a small group of people on a specific topic. An interview group size is typically four to eight individuals who participate in an interview that lasts from one-half to two hours (Patton, 1990). Focus groups are advantageous when the interaction among interviewees will likely yield the best information and when interviewees are similar to and cooperative with each other. When conducting focus groups, all participants should be encouraged to contribute (Creswell, 2002). These authors stress that a focus group is not a decision making or problem-solving group; it is truly an interview using open-ended questions. 
The following advantages and disadvantages of using focus group interviews are put

forth by Patton (1990):

It (focus group interviews) is a highly efficient qualitative data collection technique. In one hour, the evaluator can gather information from eight people instead of only one person. Thus the sample size can be increased significantly in an evaluation using qualitative methods through focus group interviewing. Focus group interviews also provide some quality controls on data collection in that participants tend to provide checks and balances on each other that weed out false or extreme views. The group's dynamics typically contribute to the focusing on the most important topics and issues in the program and it is fairly easy to assess the extent to which there is relatively consistent, shared view of the program among participants. Finally focus groups tend to be highly enjoyable to participants.

There are also some weaknesses of focus groups. Because of the amount of response time to any given question is increased considerably by having a number of people respond, the number of questions that can be asked is limited. With eight people in an hour, it is typically possible to ask no more than ten major questions. Facilitating and conducting a focus group interview requires considerable group process skills. It is important to know how to manage the interview so that it is not dominated by one or two people, and so that those participants who tend not to be highly verbal are able to share their views. (p. 335-336).

Both the advantages and disadvantages described above applied to this study, and I remained cognizant of this fact throughout my interpretation of the data and discussion of their implications. 
Figure 1

Structure of Research Design

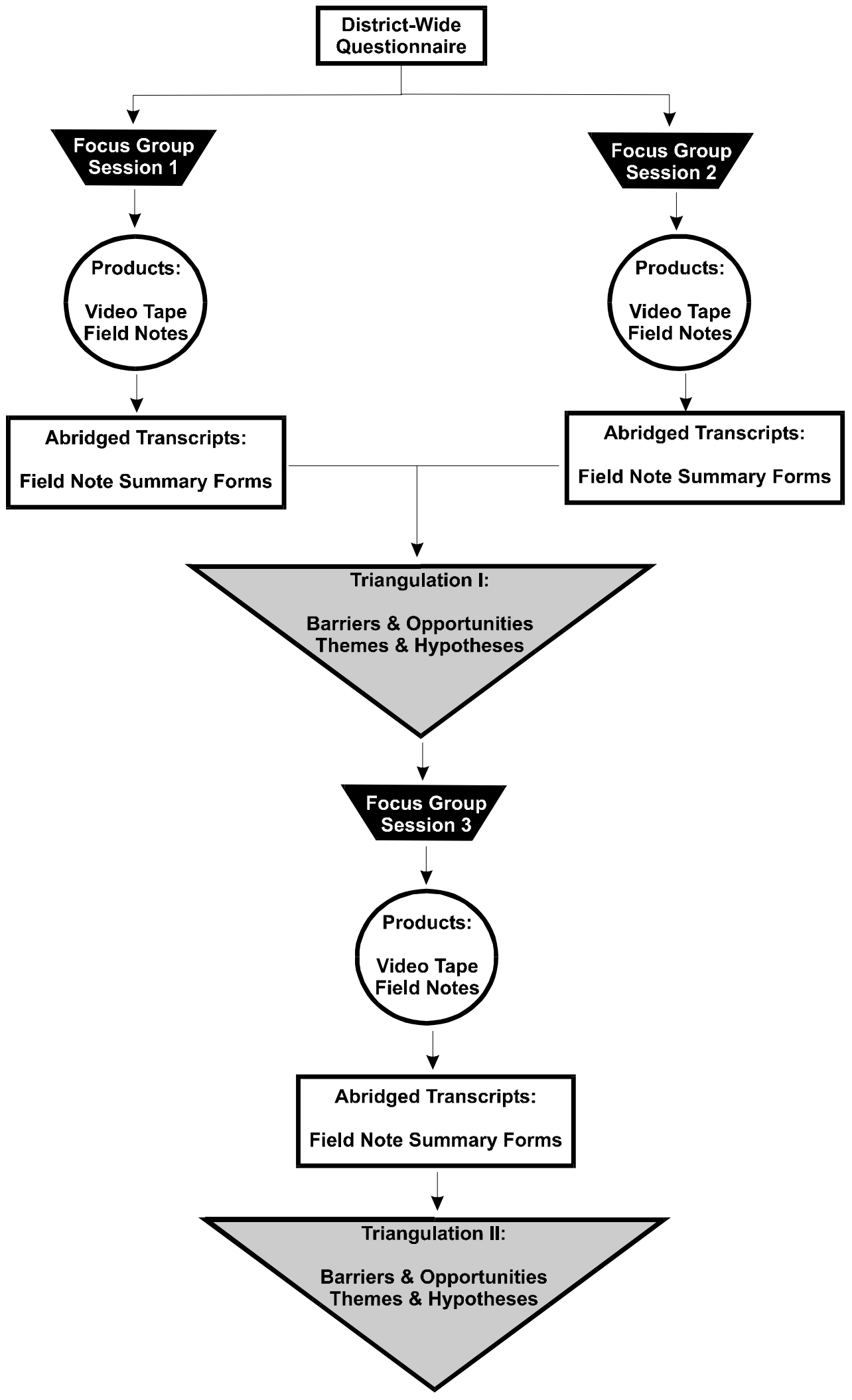


Three different focus group interviews were conducted for this study. The groups consisted of five persons in Focus Groups A1, six persons in Focus Group A2, and a combined total of ten persons for Focus Group B. The composition of the three focus groups was as follows:

Focus Group A1 (5 total)- Special education teachers in the area of moderate and severe disabilities employed at middle and high schools in the Springfield City School District, Springfield, Ohio;

Focus Group A2 (6 total)- Related health service personnel from the same middle and high schools in the Springfield City School District, Springfield, Ohio; the related health service personnel included occupational therapists, physical therapists, speech/language pathologists, and school nurses;

Focus Group B (10 total)- Combined membership of groups $1 \& 2$ following the initial two focus group interviews.

\section{Sampling}

The type of sampling for this research study was purposeful homogeneous sampling. In purposeful sampling, the researcher intentionally selects individuals or sites for investigating or understanding the central phenomenon (Creswell, 2002). The standard in choosing individuals is whether they are "information rich" (Patton, 1990, p. 169). In other words, the individuals identified for participation in the focus group are selected because they bring specific expertise or experience related to the topic under investigation. 
In this study, the participants were drawn from middle and secondary teachers and related service personnel employed by the Springfield City School District, Springfield, Ohio. This long established city school district in 2004 had a total student population of 9,081 and served 1,474 students identified as receiving special education under IDEA. There were eleven (11) elementary schools, five (5) middle schools, two (2) high schools, two (2) alternative schools, and one (1) early childhood center. The district employed 749 teachers with 113 serving as special educators; in addition, the district employed three (3) occupational therapist, two (2) physical therapist, twelve (12) speech/language pathologist, and nine (9) nurses. This school district was selected because it was recently identified as a "failing" district by the Ohio Department of Education. This designation had spurred an internal examination of programming and practices. Thus, any conclusions and recommendations that are drawn from the completed study can be beneficial to the district in implementing changes in their current programs that serve students with special needs. In addition, due to the partnership agreement with Wittenberg University (by whom I was and am currently employed as an instructor), I obtained initial permission to collect data for my dissertation (see appendix A). This was and is a long-standing, productive, and mutually beneficial partnership. Examples of the good working relationship include advisory board positions, professional development programs, a teaching associates program, adjunct faculty, field placements, and student-to-university student tutoring programs. This symbiotic relationship further increases the probability that any specific conclusions and recommendations from the proposed study will be utilized. 
As noted in the review of the literature, there exists a void in the investigation of collaborative efforts at the middle and high school levels in programs serving students with moderate and severe disabilities. So, I chose to use the entire special educator and service personnel populations for the initial questionnaire. I used the results of this questionnaire to inform and identify focus questions that were relevant, and, perhaps, specific, to middle and secondary schools. Subsequently, the focus groups were drawn from middle and high schools only and from professionals serving students with moderate and severe disabilities in these schools.

\section{Data Collection and Analysis}

Data was collected in three phases as illustrated in Figure 2. Phase I data collection consisted of a questionnaire. The results and analysis from the survey questionnaire were be used to generate questions for discussion in the second phase of data collection. Phase II data collection consist ed of two focus groups, one with special educators and one with related health service personnel. The results derived from the data collected and analyzed were used to inform the third phase of data collection. Phase III data collection consisted of a final focus group combing both special educators and related health service personnel. The final reporting of the data was derived from the interim data reports from Phases I, II and III. 
FIGURE 2 Data Collection and Coding

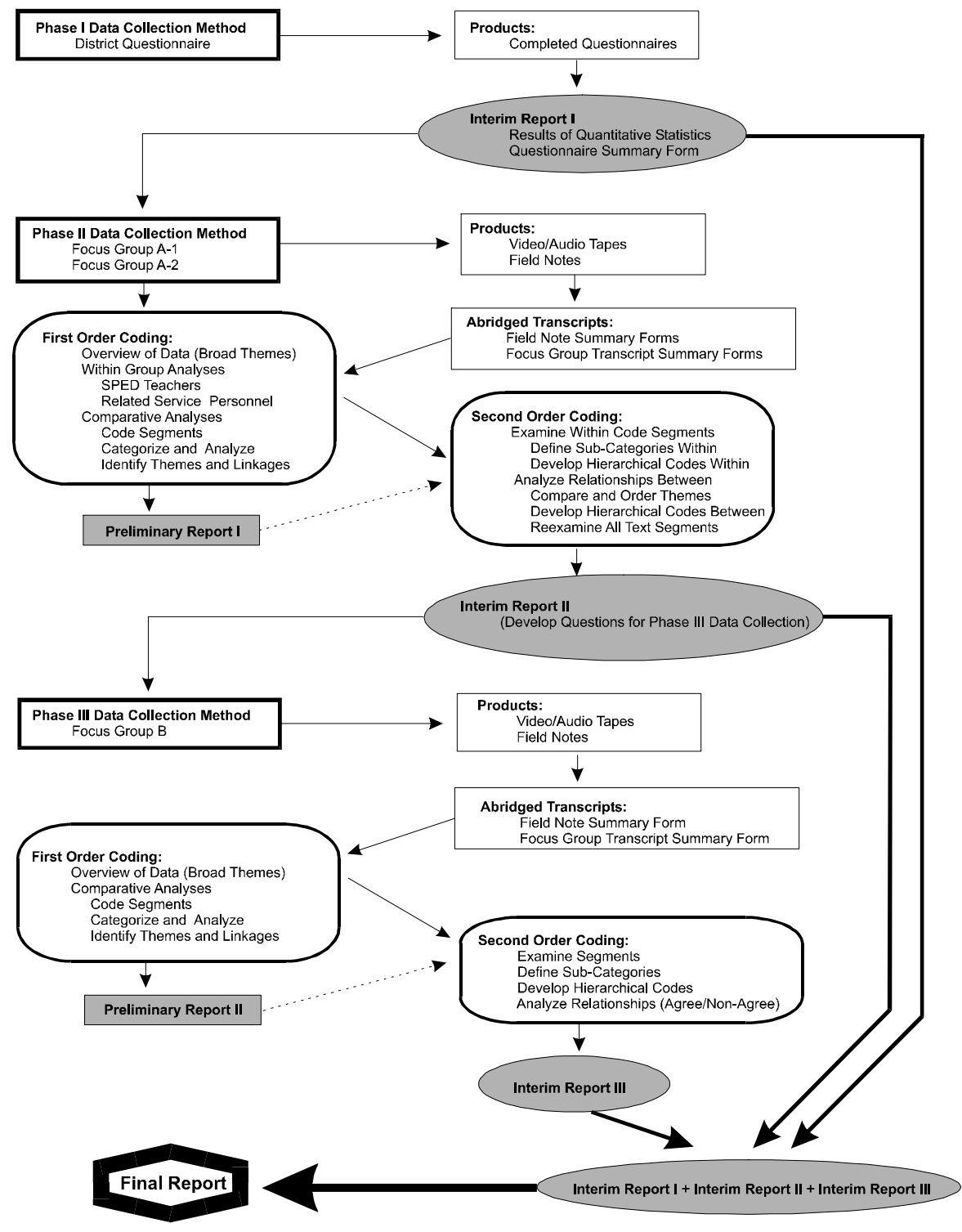


The questionnaire (see Appendix B) was distributed to all one hundred thirtythree participants (special educators and related health service personnel) at the preschool, elementary, middle, and high school levels in the school district. I designed this questionnaire specifically to investigate collaboration between special educators and related health service personnel. It was based upon the six elements of defining characteristics related to the process of collaboration as defined by Friend and Cook (2003). Data from these questionnaires were used to identify common and disparate themes among and between the groups. The questionnaire forms, together with a self-addressed postage pre-paid envelope were distributed to identified participants by the Springfield City School District's inter school mail system. Using the responses from all questionnaire participants, a mean response score was calculated for each question statement. These results were used to help paint a broad picture of the perspectives and opinions of those involved in collaboration within the entire school district. In order to get a more detailed picture of differences related to special educators versus related health service personnel and special educators involved at the preschool/elementary levels versus the middle/high school levels, specific comparisons were drawn. For each question a mean and standard deviation was calculated from the responses of each of these groups, and compared using the Kruskal-Wallis test a non-parametric statistical procedure (Creswell, 2002). The full data are displayed in Appendix E. This information was then utilized to confirm and develop questions for the initial focus groups (see Appendix C).

The specific results and broad themes derived from the questionnaire were further explored in a series of focus groups in which middle and high school special 
educators and health related services personnel who work with students with moderate and severe disabilities participated. As the principal investigator, I facilitated these three focus group interview sessions. Because I was involved in facilitating and unable to take extensive notes, an independent observer was present to record field notes. This was a senior early childhood and special education dual licensure major selected from a pool of twenty-two senior level dual licensure majors because of her background and qualifications. I selected an undergraduate student rather than a masters level student or faculty colleague to assure a relatively unbiased opinion not prejudiced by employment with a school system. All focus group interviews were videotaped for the purpose of identifying the speaker. The videotaped sessions were also transcribed and utilized for confirmation of field notes and other data analyses. The transcriber made use of a focus group seating chart (see Appendices D-1 \& D-2) in order to assist in the identification of the speakers.

As expected, the transcripts and field notes contained large amounts of data.

The next step taken in order to produce findings was qualitative content analysis.

In general, the analysis of the data from each focus group will consist of first developing a general sense of the data followed by coding and description of themes about the central question. This process is inductive, going form the particular (the detailed data) to the general (codes and themes). The final goal of this process is to generate a larger consolidated picture (Tesch, 1990).

This involved the following steps:

1. preparing and organizing the data for analysis

2. exploring the data

3. describing and developing themes from the data

4. representing and reporting the findings 
5. interpreting the findings

6. validating the accuracy and credibility of the findings

This process, which is common in qualitative research, involved repeated reviews of the data and repeated analysis with each review (Miles \& Huberman, 1994). The initial review consisted of scanning the data for general information, making notes of ideas and stimulating my thinking concerning organization of the data. The second review involved coding and categorizing the data. Coding consisted of segmenting and labeling the text of the transcription and field notes in order to form broad descriptions or themes found in the data. In contrast to the third review was used to generate additional themes and confirm themes and place these themes in hierarchical order. The object of this process was to make some initial sense of the textual data, divide them into logical segments by assigning codes, labeling the segments, examining the codes for overlap and redundancy, and, where possible collapsing these codes into themes. Thus, the data were narrowed by this inductive process into emerging themes and responses to statements.

The emerging themes from the questionnaire and from each focus group were triangulated in order to validate the findings for the final report. This triangulation process is used to make comparison within and among non-parametric data sets (Patton, 1990; Creswell, 2002). Prior to conducting the focus groups in Phase Three, transcripts and field notes from focus group sessions A1-Special Educators and A2-Related Health Services Personnel were coded and analyzed. From the emerging themes centering around barriers and opportunities, I constructed questions. In order to lend validation to the results from Phases One and Two, the 
group results were triangulated to identify convergent and divergent themes, responses and explorative questions. Further validation was sought during the focus group in Phase Three. The results of the analyses of Phase Two were revealed to the combined population that made up focus group in Phase Three. These themes and questions were the topics of discussion. Once again videotape and field notes was recorded and analyzed. In order to ensure that the final report was accurate and credible, two final triangulations were performed comparing the results of Phase Three focus group B-Combined Group with those of focus group session A-1-Special Educators and the results of focus group B-Combined Group with those of focus group session A-2-Related Health Services Personnel. A final report was produced and contained a summary of major and minor themes generated from the questionnaire and confirmed and explored through each of the focus group sessions. Perspective/Lens of the Researcher

In qualitative research it is imperative that investigator credibility be addressed (Patton, 1990; Frankfort-Nachmias \& Nachmias, 1996), that is, "the principle is to report any personal and professional information that may have affected data collection, analysis, and interpretation - either negatively or positively in the minds of the users of the findings”(Patton, 1990, p. 472). Therefore, I wish to disclose my predispositions and biases. The following factors may have colored the desired neutrality and impartiality with which I approached this study: (1) I had been employed as a special education teacher in collaborative service settings serving young children in early intervention birth to three at The Easter Seal Rehabilitation Center and served students with moderate and severe disabilities at John Marshall 
High School, both located in West Virginia; (2) I was and am currently employed as an Instructor of Special Education at Wittenberg University teaching both undergraduate and graduate students who will be asked to perform in environments where collaboration is both desired and required; and, finally, (3) this study, in part, satisfied the requirements for the Doctor of Education degree at West Virginia University. 


\section{Chapter IV}

Results

\section{Introduction}

In this chapter the results are presented in three phases: Phase One- District Questionnaire, Phase Two- Position Specific Focus Groups, and Phase ThreeCombined Focus Group. The interpretation of the results of each phase was interpreted with respect to the six guiding research questions. As noted, each sequential phase was used to develop the questions to be pursued in the subsequent phase. Thus the results of Phase Three represent confirmation and support of the data collected in Phases One and Two.

\section{Phase One: District Questionnaire}

Questionnaires were sent to all special education teachers and related health service personnel within the Springfield City School District located in Springfield, Ohio. Questionnaires were returned by 86 of the 133 possible respondents resulting in a $65 \%$ return rate. The number of respondents within each job category are contained in Table 1. 
Table 1 Questionnaire Participants

\begin{tabular}{|l|c|c|}
\hline \multicolumn{1}{|c|}{ Position } & Number & $\begin{array}{c}\text { Percent } \\
\text { Returned }\end{array}$ \\
\hline Special Education Teachers & & \\
Preschool & $24 / 42$ & $57 \%$ \\
Elementary & $22 / 33$ & $67 \%$ \\
Middle & $13 / 22$ & $59 \%$ \\
High School & & \\
\hline Related Health Personnel & $2 / 2$ & $100 \%$ \\
Physical Therapist & $2 / 3$ & $67 \%$ \\
Occupational Therapist & $8 / 12$ & $67 \%$ \\
Speech Pathologist & $8 / 9$ & $89 \%$ \\
Nurse & $86 / 133$ & $65 \%$ \\
\hline TOTAL & & $70 \%$ \\
\hline
\end{tabular}

Significant differences $(p<0.05)$ among the groups were identified on seven (7) survey statements. These were statements numbered 2,3,5,11,12,21, \& 23. On the remainder, no significant differences among the groups were found. For these results, questions for which the mean score rounded to greater than or equal to four $(\geq 4)$ were deemed to be in agreement with the statement; statements for which the mean score rounded to less than or equal to two $(\leq 2)$ were deemed to be in disagreement with the statement. Those statements that rounded to three were taken to indicate no consensus among the respondents. (See Table 2.) 
Table 2 Questionnaire Statements Rounded Agreement, Disagreement \& No Consensus

\begin{tabular}{|c|c|c|c|c|c|}
\hline Statement & Mean & $\begin{array}{l}\text { Standard } \\
\text { Deviation }\end{array}$ & $\begin{array}{l}\text { Agree } \\
\text { Rounded } \\
(\geq 4)\end{array}$ & $\begin{array}{l}\text { No } \\
\text { Consensus }\end{array}$ & $\begin{array}{l}\text { Disagree } \\
\text { Rounded } \\
(\leq 2)\end{array}$ \\
\hline $\begin{array}{l}\# 1 \text { There is sufficient time in my daily school } \\
\text { schedule to develop collaborative } \\
\text { interactions. }\end{array}$ & 2.3 & 1.2 & & & 2 \\
\hline $\begin{array}{l}\text { \#4 My definition of collaboration matches } \\
\text { that of the teachers with whom I work. }\end{array}$ & 3.2 & 1.0 & & 3 & \\
\hline $\begin{array}{l}\text { \#6 Collaboration with others is worth the } \\
\text { time and effort in producing optimal } \\
\text { outcomes for the student with special needs. }\end{array}$ & 4.5 & 0.7 & 5 & & \\
\hline $\begin{array}{l}\text { \#7 Collaboration allows for the generation of } \\
\text { creative solutions to issues and problems. }\end{array}$ & 4.5 & 0.7 & 5 & & \\
\hline $\begin{array}{l}\# 8 \text { I have had adequate training in the } \\
\text { methods of collaboration. }\end{array}$ & 3.4 & 1.1 & & 3 & \\
\hline $\begin{array}{l}\text { \#9 Collaboration is critical to meeting the } \\
\text { needs of students and families. }\end{array}$ & 4.5 & 0.6 & 5 & & \\
\hline $\begin{array}{l}\text { \#10 All members of collaborative teams } \\
\text { participate equally. }\end{array}$ & 2.8 & 1.2 & & 3 & \\
\hline \#13 Collaboration is voluntary. & 3.0 & 1.1 & & 3 & \\
\hline $\begin{array}{l}\text { \#14 Collaboration requires parity (equal } \\
\text { participation) among participants. }\end{array}$ & 3.9 & 1.0 & 4 & & \\
\hline \#15 Collaboration is based on mutual goals. & 4.1 & 0.7 & 4 & & \\
\hline $\begin{array}{l}\# 16 \text { Collaborating depends on shared } \\
\text { responsibility for participation and decision } \\
\text { making. }\end{array}$ & 4.2 & 0.7 & 4 & & \\
\hline $\begin{array}{l}\text { \#17 Individuals who collaborate share } \\
\text { resources. }\end{array}$ & 4.0 & 0.9 & 4 & & \\
\hline $\begin{array}{l}\text { \#18 Individuals who collaborate share } \\
\text { accountability for outcomes. }\end{array}$ & 3.9 & 0.9 & 4 & & \\
\hline $\begin{array}{l}\text { \#19 My immediate supervisor understands } \\
\text { the amount of collaboration required to } \\
\text { serve my students. }\end{array}$ & 3.4 & 1.1 & & 3 & \\
\hline $\begin{array}{l}\text { \#20 Our school district places a high priority } \\
\text { on collaborative efforts between teacher and } \\
\text { therapist. }\end{array}$ & 2.6 & 1.2 & & 3 & \\
\hline $\begin{array}{l}\text { \#22 I am satisfied with my own collaborative } \\
\text { efforts. }\end{array}$ & 3.6 & 1.0 & 4 & & \\
\hline $\begin{array}{l}\text { \#24 Collaboration is recognized and } \\
\text { rewarded by my school system. }\end{array}$ & 2.4 & 1.0 & & & 2 \\
\hline $\begin{array}{l}\text { \#25 I have ample time and opportunity to } \\
\text { develop collaborative relationships. }\end{array}$ & 2.2 & 1.1 & & & 2 \\
\hline $\begin{array}{l}\text { \#26 Collaborators are able to maintain } \\
\text { professional attitudes; personal differences } \\
\text { do not impede the workings of the group. }\end{array}$ & 3.1 & 1.1 & & 3 & \\
\hline $\begin{array}{l}\text { \#27 I am aware of the relevant federal } \\
\text { legislation that requires collaboration among } \\
\text { service providers. }\end{array}$ & 3.2 & 1.2 & & 3 & \\
\hline
\end{tabular}


Respondents exhibited general agreement with a total of nine (9) statements. From review of these results the statement were grouped under three emergent and overarching themes. These statements fell into the three following themes:

theme A- value of collaborative programming (statement \#s 6,7, \& 9)

\#6- Collaboration with others is worth the time and effort in producing optimal outcomes for the student with special needs.

\#7- Collaboration allows for the generation of creative solutions to issues and problems.

\#9- Collaboration is critical to meeting the needs of students and families.

For theme A, value of collaborative programming, there was strong agreement across all groups. This indicated that participants viewed collaboration as critical for the generation of effective programming and worth the time and effort required. This was indicated by means of the answers and the tight standard deviation shown in Table 2.

theme B- mutuality of goals and sharing participation \& resources (statement \#s $14,15,16,17, \& 18)$

\#14- Collaboration requires parity (equal participation) among \#15- Collaboration is based on mutual goals. \#16- Collaborating depends on shared responsibility for participation and decision making.

\#17- Individuals who collaborate share resources. \#18- Individuals who collaborate share accountability for outcomes. 
For theme B, mutuality of goals and sharing participation \& resources, there was strong agreement across all groups. This indicated that participants recognized the value of parity and shared accountability among collaborators. This was indicated by means of the answers and the tight standard deviation shown in Table 2.

theme C- level of personal satisfaction (statement \# 22)

\#22- I am satisfied with my own collaborative efforts.

For theme C, level of personal satisfaction, there was some agreement across the groups. This indicated that as individuals participants were satisfied with their own collaborative efforts. This was indicated by the mean of 3.6 rounded to 4 and a larger variability as indicated by the standard deviation. (See Table 2.)

In general, respondents disagreed with the following three (3) statements which dealt with time, reward, and recognition:

\#24- Collaboration is recognized and rewarded by my school system.

\#25- I have ample time and opportunity to develop collaborative relationships.

\#1- There is sufficient time in my daily schedule to develop collaborative interactions .

These results indicated that the lack of available time, recognition, and reward may be barriers to collaborative efforts.

The responses to the following eight (8) statements varied greatly within each group and the mean responses indicated no opinion that could be generalized between or among the groups: 
\#4 - My concept of collaboration matches that of the teachers with whom I work.

\#8- I have had adequate training in the methods of collaboration.

\#10- All members of collaborative teams participate equally.

\#13- Collaboration is voluntary.

\#19- My immediate supervisor understands the amount of collaboration required to serve my students.

\#20- Our school district places a high priority on collaborative efforts between teacher and therapist.

\#26- Collaborators are able to maintain professional attitudes; personal differences do not impede the workings of the group.

\#27- I am aware of the relevant federal legislation that requires collaboration among service providers.

In contrast to the responses described above, significant differences were found among groups for seven (7) statements. This was determined by using the Kruskal-Wallis Test which is a non-parametric test used to compare three or more independent groups of sampled data. These survey statements were clustered as the following themes:

theme D- team membership \& availability

theme E- concepts of roles \& responsibilities

theme F- administrative support

theme G- personal satisfaction 
For theme D, these two statements addressing team membership and availability of team members were as follows:

\#11- Membership on collaborative teams is appropriate at my school. \#12- Necessary team members are available to participate in decision making.

The rank ordering of the mean responses for each group and the accompanying frequency histogram are presented below. 


\begin{tabular}{|l|l|l|}
\hline$\# 11-$ Membership on collaborative teams is appropriate at my school $\boldsymbol{p}=\mathbf{0 . 0 4 3}$ \\
\hline Position & Mean & Standard Deviation \\
\hline Nurse & 4.250 & 0.707 \\
\hline Preschool Teacher & 4.143 & 1.069 \\
\hline Therapist & 3.917 & 0.793 \\
\hline High School Teacher & 3.385 & 1.261 \\
\hline Middle School Teacher & 3.273 & 1.162 \\
\hline Elementary School Teacher & 3.200 & 1.080 \\
\hline
\end{tabular}

\section{Statement 11}

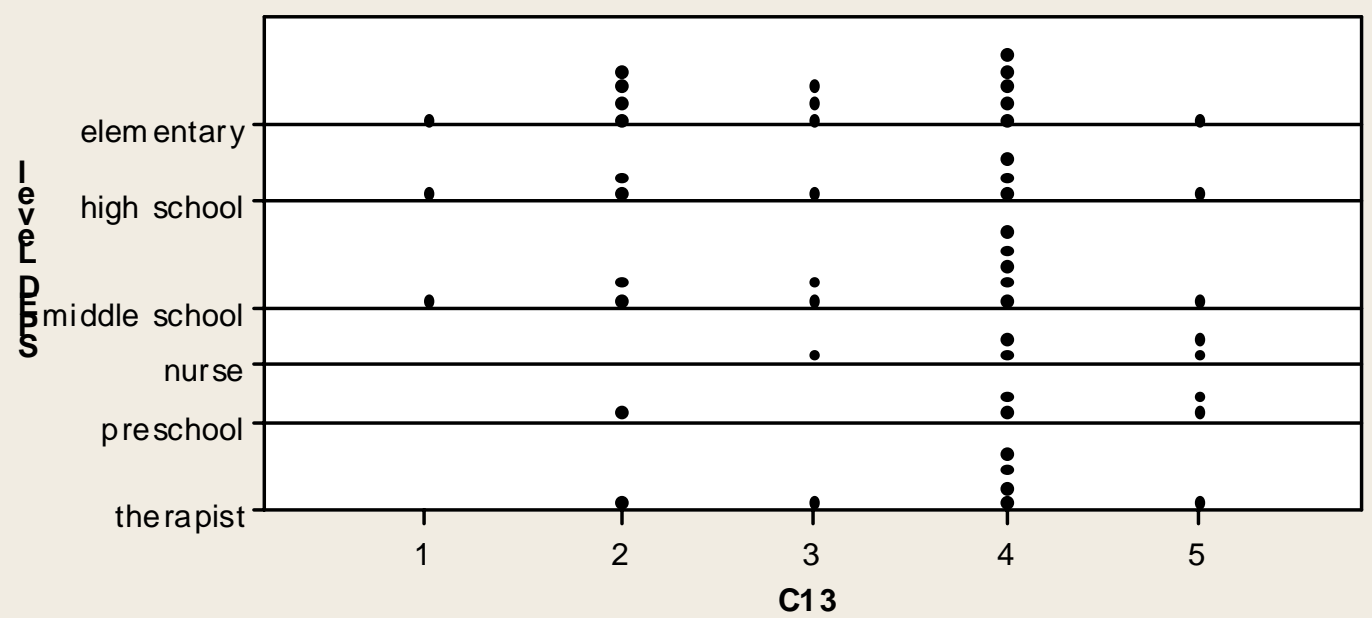




\begin{tabular}{|l|l|l|}
\hline$\# 12-$ Necessary team members are available to participate in decision making $\boldsymbol{p}=\mathbf{0 . 0 1 5}$ \\
\hline Position & Mean & Standard Deviation \\
\hline Nurse & 4.000 & 0.926 \\
\hline Preschool Teacher & 3.857 & 1.069 \\
\hline Elementary Teacher & 3.400 & 0.913 \\
\hline Therapist & 3.250 & 1.288 \\
\hline High School Teacher & 2.692 & 1.109 \\
\hline Middle School Teacher & 2.636 & 1.255 \\
\hline
\end{tabular}

\section{Statement 12}

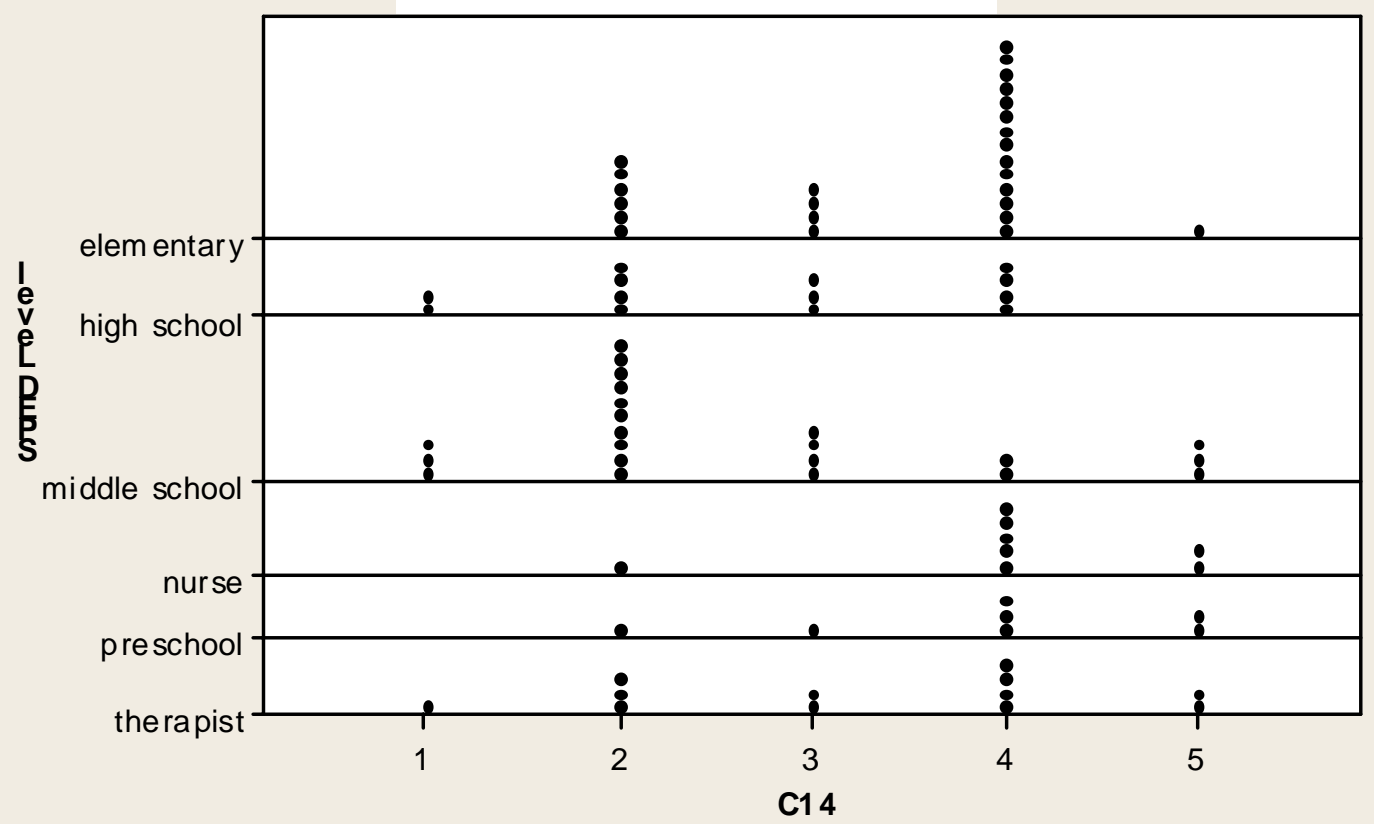


These results indicated that nurses, therapists and preschool teachers agreed strongly that collaborative team membership is appropriate for the students that they serve. The nurses and preschool teachers also felt that necessary team members are available. However, the therapists' opinions were highly variable and span the entire range of responses. On the other hand, elementary, middle and high school teachers expressed far less confidence that the make-up of the collaborative team is appropriate; middle and high school teachers in particular responded that team members are less readily available.

For theme $\mathbf{E}$, these three statements dealing with the concept of role and responsibility were as follows:

\#3- Other members of collaborative groups clearly understand their roles and responsibilities.

\#5- My concept of collaboration matches that of the therapist with whom I work. \#23- Teachers and therapists are viewed as equal partners in collaborating.

The rank ordering of the mean responses for each group and the accompanying frequency histogram are presented below. 


\begin{tabular}{|l|l|l|}
\hline $\begin{array}{l}\text { \#3- Other members of collaborative groups clearly understand their roles and } \\
\text { responsibilities }\end{array}$ \\
\hline Position & Mean & \multicolumn{1}{c|}{$\mathbf{0 1 6}$} \\
\hline Preschool Teacher & 4.000 & Standard Deviation \\
\hline Elementary School Teacher & 3.520 & 0.577 \\
\hline Nurse & 3.500 & 1.005 \\
\hline High School Teacher & 3.000 & 0.756 \\
\hline Therapist & 2.833 & 1.155 \\
\hline Middle School Teacher & 2.682 & 1.193 \\
\hline
\end{tabular}

\section{Statement 3}

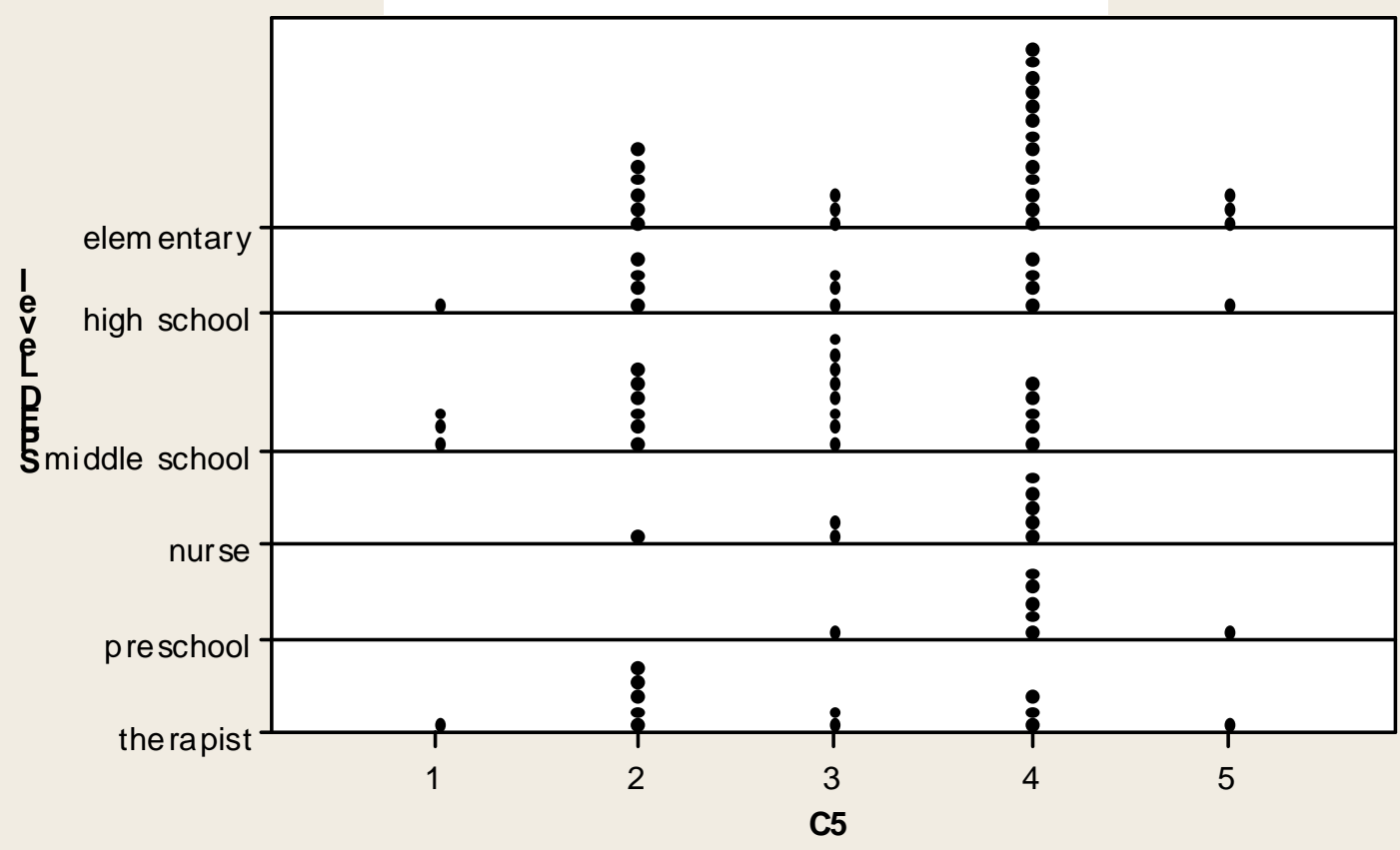




\begin{tabular}{|l|l|l|}
\hline \#5- My concept of collaboration matches that of the therapist with whom I work $\boldsymbol{p}=\mathbf{0 . 0 1 7}$ \\
\hline Position & Mean & Standard Deviation \\
\hline Therapist & 4.083 & 0.900 \\
\hline Nurse & 4.000 & 0.926 \\
\hline Preschool Teacher & 3.857 & 0.690 \\
\hline Middle School Teacher & 3.409 & 0.959 \\
\hline Elementary School Teacher & 3.080 & 0.707 \\
\hline High School Teacher & 3.077 & 0.862 \\
\hline
\end{tabular}

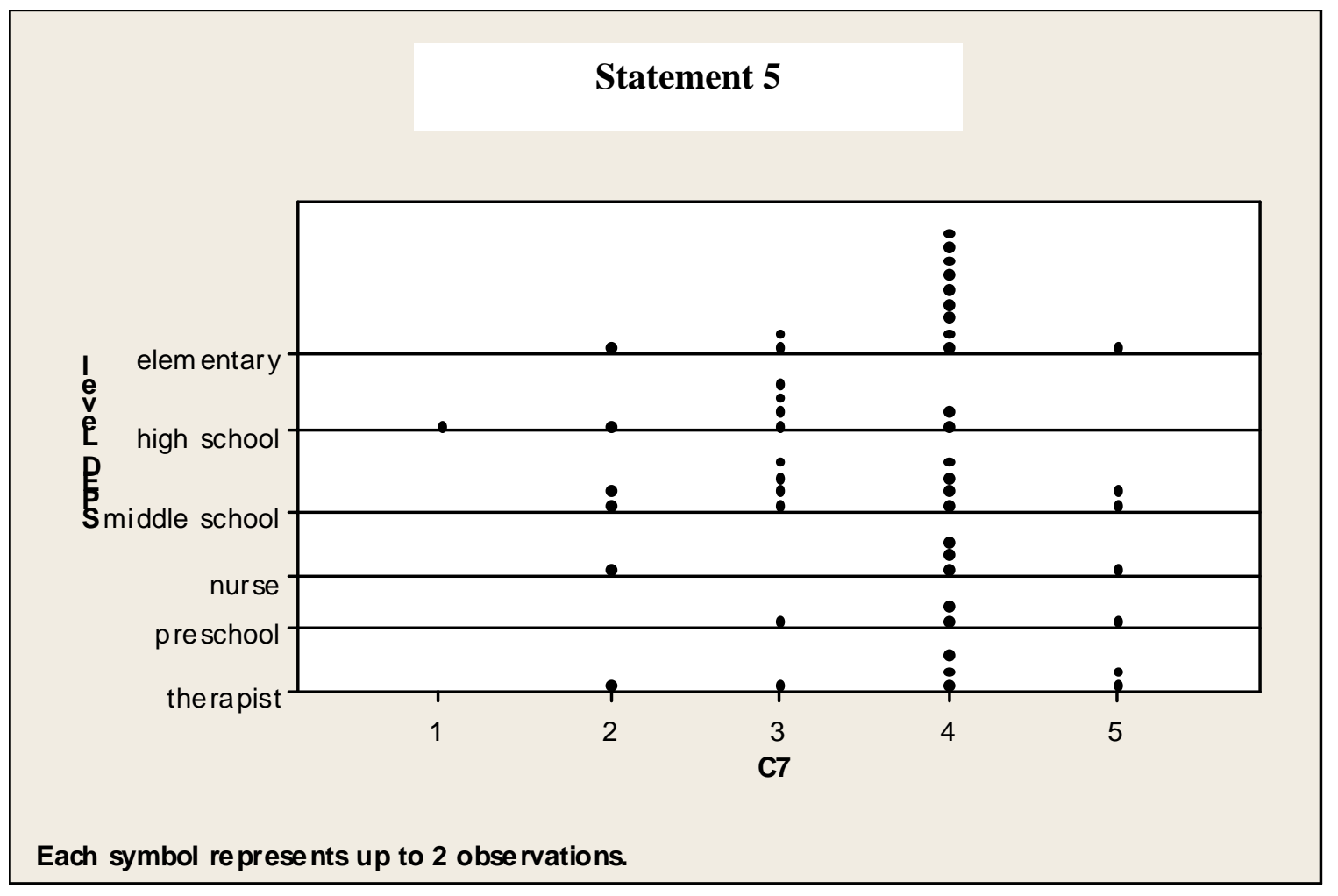




\begin{tabular}{|l|l|l|}
\hline \#23- Teachers and therapists are viewed as equal partners in collaborating $\boldsymbol{p}=\mathbf{0 . 0 1 0}$ \\
\hline Position & Mean & Standard Deviation \\
\hline Preschool Teacher & 4.571 & 0.535 \\
\hline Nurse & 4.000 & 0.756 \\
\hline Elementary School Teacher & 3.600 & 0.913 \\
\hline Therapist & 3.333 & 1.231 \\
\hline High School Teacher & 3.154 & 0.987 \\
\hline Middle School Teacher & 3.091 & 1.151 \\
\hline
\end{tabular}

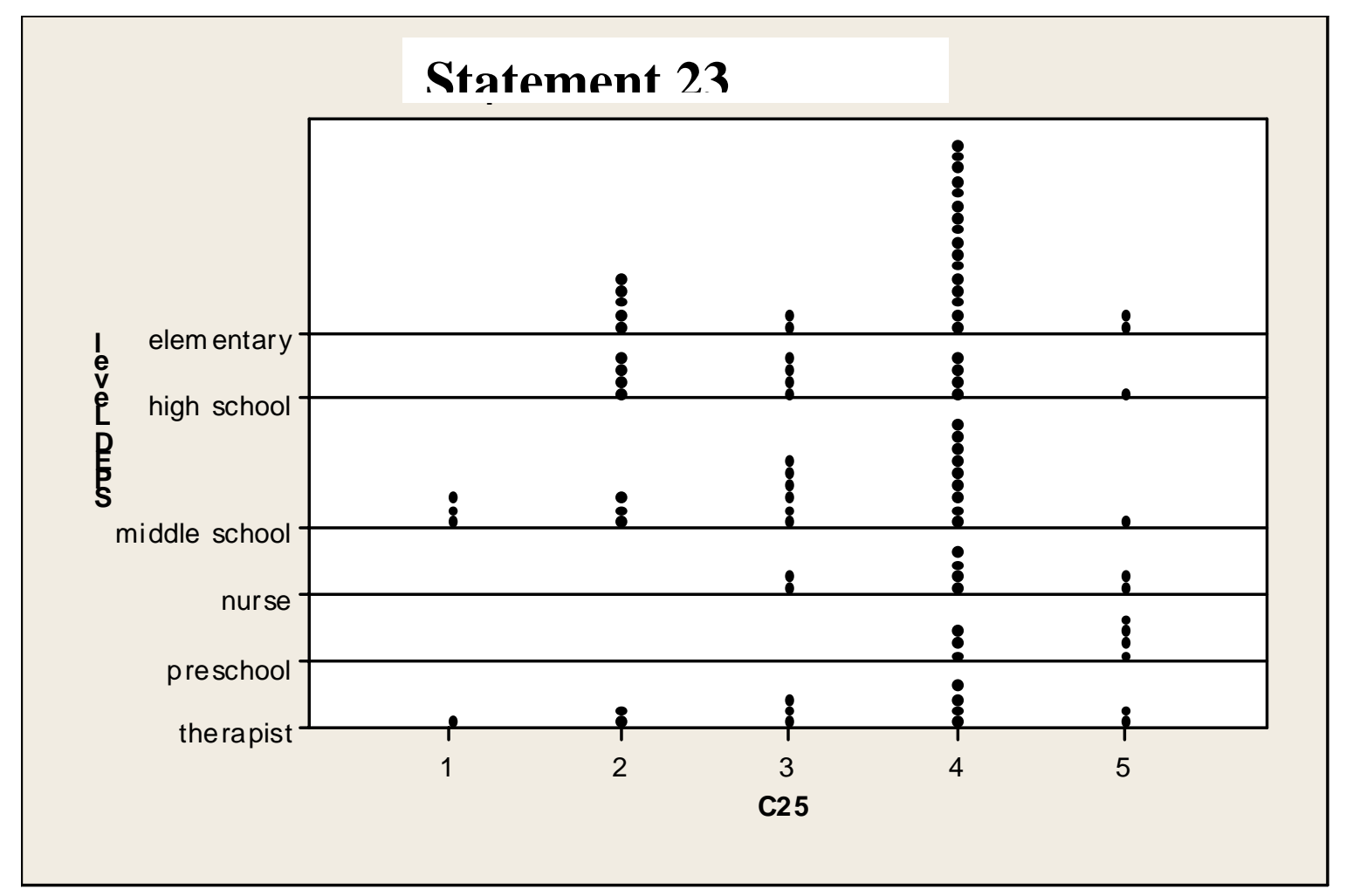


These results indicated that preschool teachers had a clearly higher level of agreement than the other groups that collaborative group understand their roles and responsibilities. While middle school teachers, high school teachers, and therapists did not clearly disagree, their responses indicated less confidence in this area. Nurses and elementary teachers appeared to be variable in their responses.

Results related to a mutual collaborative relationship with therapists with whom others work indicated that nurses, therapists, and preschool teachers agree; while elementary, middle and high school teachers expressed less agreement bordering on "no opinion”.

Results related to being viewed as equal partners when collaborating indicated that preschool teachers, elementary teachers, and nurses agreed and differed from middle and high school teachers. The latter two groups again bordered on "no opinion”. It is interesting to note that the responses of therapists, who serve across grade levels were variable, expressing only very slight agreement.

For theme $\mathbf{F}$, this statement dealing with administrative support was as follows:

\#2- My collaborative efforts are fostered and supported by the administration.

The rank ordering of the mean responses for each group and the accompanying frequency histogram are presented below. 


\begin{tabular}{|l|l|l|}
\hline \#2- My collaborative efforts are fostered and supported by the administration $\boldsymbol{p}=\mathbf{0 . 0 2 2}$ \\
\hline Position & Mean & Standard Deviation \\
\hline Preschool Teacher & 4.429 & 0.535 \\
\hline Nurse & 4.125 & 0.354 \\
\hline Elementary School Teacher & 3.520 & 1.159 \\
\hline High School Teacher & 3.231 & 1.235 \\
\hline Middle School Teacher & 3.136 & 1.125 \\
\hline Therapist & 3.083 & 1.165 \\
\hline
\end{tabular}

\section{Statement 2}

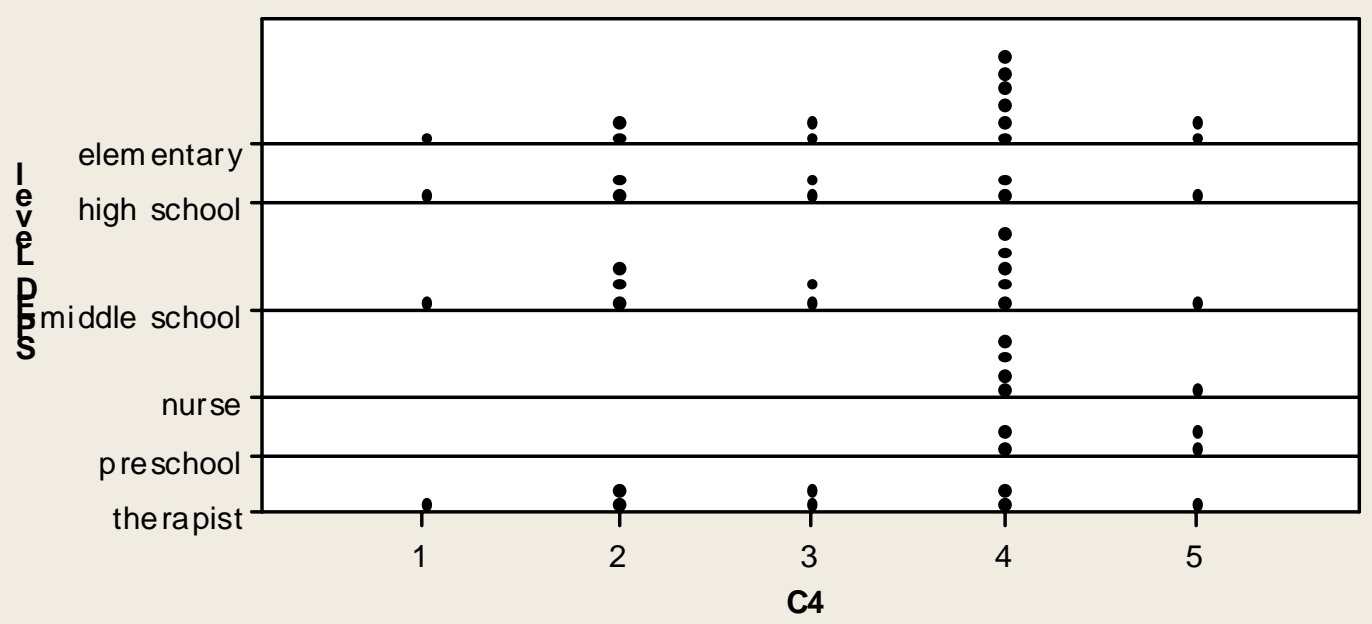

Each symbol represents up to 2 obse rvations.

These results indicated that nurses and preschool teachers were highly satisfied with the availability of administrative support. However, the level of satisfaction expressed by therapists, elementary, middle and secondary teachers was considerably less. 
For theme $\mathbf{G}$, this statement dealing with personal satisfaction was as follows:

\#21- I derive personal satisfaction from my collaborative efforts.

The rank ordering of the mean responses for each group and the accompanying frequency histogram are presented below.

\begin{tabular}{|l|l|l|}
\hline \#21- I derive personal satisfaction from my collaborative efforts & P=0.037 \\
\hline Position & Mean & Standard Deviation \\
\hline Nurse & 4.500 & 0.535 \\
\hline Preschool Teacher & 4.286 & 0.756 \\
\hline Therapist & 4.000 & 0.603 \\
\hline Elementary School Teacher & 3.760 & 0.831 \\
\hline High School Teacher & 3.692 & 0.751 \\
\hline Middle School Teacher & 3.545 & 0.912 \\
\hline
\end{tabular}

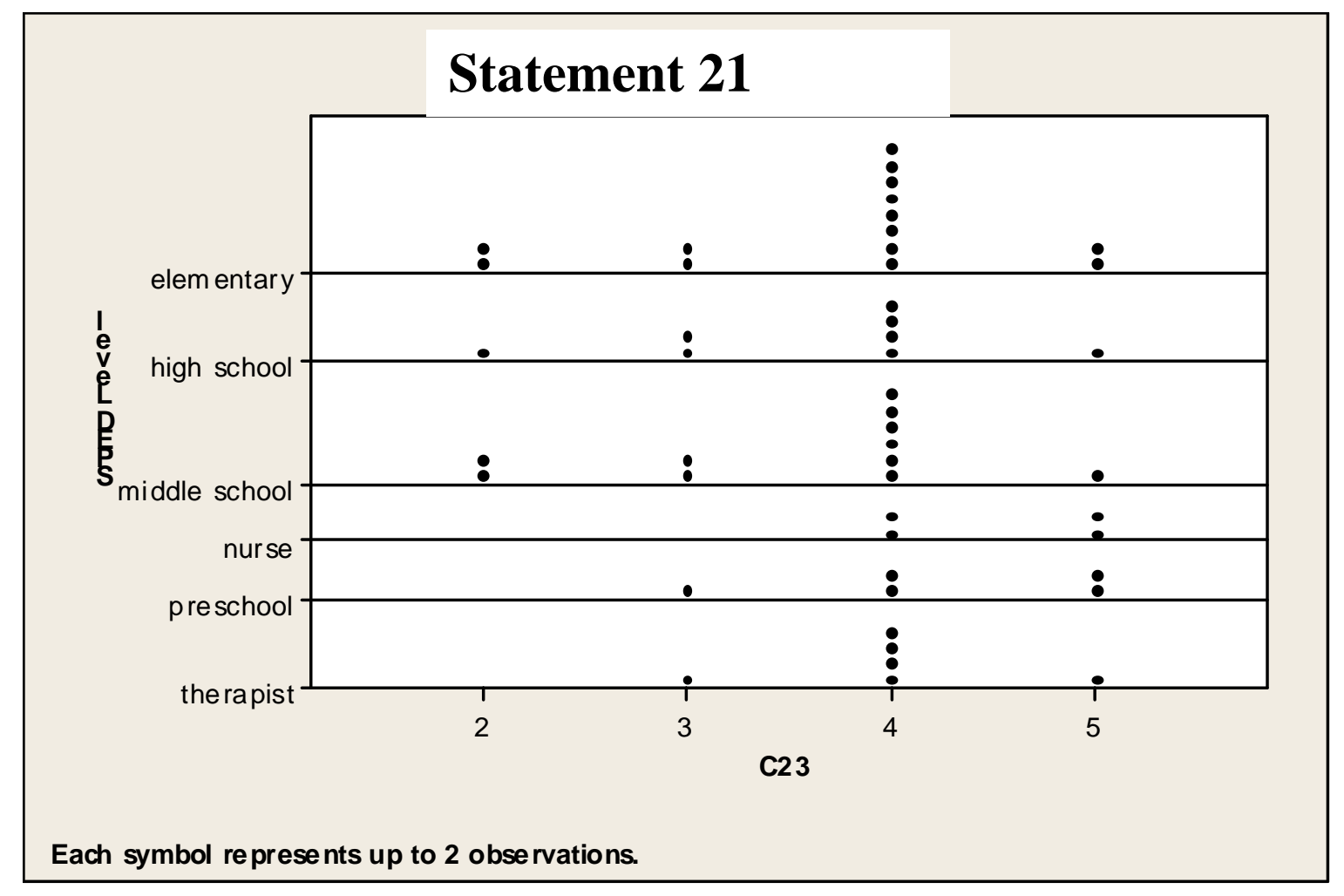


These results indicated that nurses, therapists and preschool teachers expressed the highest levels of satisfaction; while elementary, middle and secondary teachers appear to be more variable

Sixty-three of the eighty-six questionnaires returned (73\%) contained a response to the open-ended question, "In your own words, how would you define collaboration?” Upon examination and coding of these responses across all participants, no distinctive differences between the responses of special education teachers and related health service personnel were identified. Rather, the many definitions of collaboration shared some common elements. These common elements included the following:

- Collaboration is goal oriented.

- Collaboration is team-driven.

- Collaboration is student-oriented.

- Collaboration involves problem solving.

- Collaboration is a shared process.

- Collaboration addresses needs.

- Collaboration is ongoing.

Other elements of the definitions of collaboration were cited much less frequently, but were deemed to be noteworthy by me through the coding of the data. These important elements included:

- The inclusion of parents as collaborative team members.

- The inclusion of the special education student him- or herself as one of the collaborative team members. 
- The important role of administrators in successful collaborations.

- The requirement for role-release among participants.

- Successful collaborative efforts involve both school and community participants.

From the survey results and the definitions of collaboration described above, I developed the following specific questions and follow-up questions for use in Phase Two (focus groups A-1: middle and high school special education teachers and A-2: related health service personnel working at the middle and secondary levels) data collection.

- Is sufficient time available to collaborate?

- Do you make use of it?

- How is collaboration recognized and rewarded?

- What rewards would you suggest?

- Do you find that the time that you spend collaborating is worthwhile?

- If so, then why?

- If not, then why not?

- During your collaborative efforts do the following occur:

- development of mutual goals?

- sharing of responsibility and decision making?

- input from all members?

- Are you satisfied with your own efforts when collaborating?

- Why or why not? 
Phase Two: Position Specific Focus Groups- A-1 \& A-2

All potential focus group members working at the middle and high school levels with students having moderate and severe disabilities were contacted and agreed to participate. Unfortunately, the regular nurse at the high school was in the end unable to participate in focus group A-2. With this single exception, focus groups consisted of all the potential participants from the school district. The two focus groups during this phase of data collection were comprised of the following:

\section{Focus Group A-1: Special Educators (total 5)}

3 middle school special education teachers (moderate/severe)

2 high school special education teachers (moderate/severe)

\section{Focus Group A-2: Related Health Services Personnel (total 6)}

2 nurses (1 middle school level \& 1 special needs nurse)

1 occupational therapist

1 physical therapist

2 speech \& language pathologists

In these focus groups the same questions were asked of both the teachers and the related health services personnel. The analysis of the responses to the questions and representative and supporting quotations are presented below.

Question 1: Is sufficient time available to collaborate?

Special Education Teachers: The overwhelming response from all of the teachers regarding the availability of time conducive for effective collaboration was a resounding “no.” Reasons given for this included the teachers' tightly scheduled time during a day and the often mismatched schedules of the teachers, nurses, and 
therapists. When time for one presents itself, other members of the collaborative team are often busy or unavailable. See selected quotes on this topic below.

"Finding adequate time or times to collaborate. Although collaboration is many times done in informal settings, a specific or scheduled collaboration time would enhance services especially for specific students or issues.”

"From my experience, time to collaborate should be granted on a needs basis."

"While I may have time in my day, the related health providers are only in my building on certain days and times, many of which are during my instruction blocks."

"We don’t talk, nor do we have time to."

"As for time, often the service providers don't have enough time to give the student to be very effective. It's because they have too many other students at many different locations to truly meet their needs. Overall, there is not enough time in the school day to communicate."

"I feel that, in the district, time is not given to for the collaborative relationships necessary to provide adequate services for our special education students, and collaboration with the regular education teachers is almost nonexistent.”

"We have no planned communication time."

Related Health Service Personnel: When this group was queried with respect to the availability of sufficient time to collaborate, the response was again a resounding "no.” Without exception all six participants responded that their caseloads prevented them from collaborating at the level that they would desire. Without a reduction in caseload or greater assistance, the percentage of their efforts devoted to collaboration will remain unchanged, or probably erode further. See selected supporting quotes:

"No! Time is the biggest problem."

"I have to serve several schools within the district. Traveling to and from buildings takes a chunk of my time." 
“Our caseloads and required paperwork cannot be accomplished in a 40 to 50 hour work week. Adding collaborative hours for each student is an unrealistic goal. I serve 60 speech students who would need to be met and planned about."

"We need a decrease in caseload, or assistants to some to help with required tasks. Basically, it's not working and that is why there are so many (job) openings the city."

"We have absolutely no time for collaboration. With pullout and inclusion four and one-half days per week, it leaves no time for common planning. My half day planning is taken up with MFEs (multi-factored evaluations) and IEP writing."

“I'm very happy in my unique role as a school nurse that I am able to attend IEPs, MFEs and other team meetings, but most of the nurses don't have this ability. The problem is that I have 1200 students in different building and I don't have enough time for everything."

From these observations, I concluded that the outlook of teachers differed from that of the related health service providers. The teachers appeared to hold out hope that their schedules might be optimized to allow a greater participation in collaborative efforts. Evidenced by statements such as:

"Although collaboration is many times done in informal settings, a specific or scheduled collaboration time would enhance services especially for specific students or issues.”

"While I may have time in my day, the related health providers are only in my building on certain days and times, many of which are during my instruction blocks.”

"It's because they have too many other students at many different locations to truly meet their needs."

The related health personnel, on the other hand, stated unequivocally that their schedules are overburdened with insufficient time for collaboration. Supported by the following statements: 
"Our caseloads and required paperwork cannot be accomplished in a 40 to 50 hour work week."

"Basically, it's not working and that is why there are so many (job) openings the city."

"We have absolutely no time for collaboration."

In order to confirm these impressions, I decided to explore this in the combined focus group in Phase Three using the following prompting question: Given the fact that you value collaboration and note that finding sufficient time is a problem, could you re-arrange your schedule to allow more time for collaboration. If yes, how?; If no, what would make this possible?

Question \#2: How is collaboration recognized and rewarded by the administration?

Both groups noted a lack of administrative support. Special education teachers and related health services personnel reported a lack of building level and district level of support and or understanding. In fact, they expressed a sense of frustration with the mixed messages sent by the district. This was evidenced by the following quotations from teachers and related services personnel.

Special Education Teachers:

“I don't think that the district cares. We are on our own to collaborate with other professionals. I think that the district just expects us to hand-off students without talking to each other.”

"I feel that the attitude toward collaboration needs to start at the top. If my principal valued it, then the staff would too."

"The administration says it is all willing to support collaboration, but they do not follow through with the efforts to make it work."

"Our administration thinks that they provide time in our schedules with waiver day and team planning. I do not feel that they set high expectations for collaboration, not do they encourage it." 
"My supervisor is very good and knows the laws and adamantly follows them. She is leaving at the end of this year and I wonder what will happen. She is one of the few in the administration who gets it."

\section{Related Health Services Personnel}

"I have a lack of support from building level administration. My building principals still don't understand that speech and language therapy is a handicapping condition and that it follows the same guidelines as other disabilities. Therefore they don't think that I need to talk to other people.”

"My building principals don't seem to care to collaborate themselves. They don't care to come to required meetings, let alone understand my need to collaborate."

"I have found that the principals understand the need for collaboration, but they say that the district administrators don't get it."

“The district just expects it to work.”

From these observations, I concluded that both special education teachers and related health services personnel perceived there to exist a definite lack of administrative support for collaborative efforts. In order to confirm these impressions, I decided to explore this in the combined focus group in Phase Three.

Question \#4: During your collaborative efforts do the following occur? (development of mutual goals, sharing of responsibilities \& decision making, input from all members)

The special education teachers tended to have a uniform perspective on the development of mutual goals, the sharing of responsibilities, and having input on decision making from all. On the other hand, the related health services personnel expressed more divergent opinions. 
Special Education Teachers: In general, believed that these activities above were desirable elements and occurred the majority of the time. This was evidenced in the following statements.

"I have not had any problems with teaming. Everyone seems to know what they are are responsible for.”

"The therapist that I work with value collaboration like I do. We are careful to make sure that everyone is informed. We really try to focus on the students and their programming."

"I think that we all handle our roles on a professional level. All team members should be respectful and treated like equal providers."

A few instances were noted where one or more important elements were compromised. However, this appeared to be minimal and linked to specific incidences.

"Throughout my experiences at various schools, collaboration has been a very important topic that was beginning to be implemented. However, this year with my teaching middle school for Springfield City, I have seen both positive and negative aspects of collaboration. I feel that all people need to participate equally when it involves special education students, but I have found some regular education teachers who don't feel the same way. They don't want to deal with the added responsibility in their classroom.”

"During inclusion this year, I needed to collaborate with the regular education teachers to meet my students' needs, but my opinions and ideas never mattered. I was often belittled. This is the first time that I have had this happen in five years of teaching."

Related Health Service Personnel: It was evident from the questionnaire that the perspective of the nurses differed form that of other related health service personnel, and more closely resembled that of the teachers described above. This same difference was also found during the focus group. It is reflected in the following quotations from the two nurses. 
"I've never had a problem with people understanding their role or responsibility. As a nurse, I don't usually have problems contacting different agencies or doctors. The therapists are always helpful and flexible and cooperative. I think the teachers and I work well together because they really need my assistance with the medical needs of their students. We all understand that we are in this together."

From my experiences, I've not had problems with teachers and therapists. We all work well together and respect each other."

The remaining related health personnel expressed a divergent opinion. In general, they felt that quite often one or more of the elements were lacking. The following quotes illustrate this perception.

"I think that sometimes therapists think differently than the teachers. We are more consultative and they expect us to spend more time.”

"I have worked with some teachers who have refused to follow-up on anything that I recommended for the students. They don't seem to understand the concept of working as a team.”

"I have experienced misunderstanding of responsibilities, and no follow through from special education teachers--not all teachers--but some are more difficult to work with than other.”

"I believe that sometimes there are communication glitches that impede the team working well together."

Question \#3: Do you find that the time collaborating is worthwhile?

Question \#5: Are you satisfied with your own collaborative efforts?

Special Education Teachers and Related Health Services Personnel: The two focus groups did not differ with respect to their answers to these two questions. All found collaboration worthwhile and were satisfied with their personal efforts. The following quotes are indicative of their attitudes.

"It is worthwhile when it works for the student." 
"I enjoy working with others and talking about the student that we serve.”

"I like the opportunity to discuss ideas with others. When I work with other therapists, I find that I am able to stay up to date on new augmentative speech devices."

“The time spent collaborating is definitely worth it. We just don’t have enough time."

"I believe that two are better than one. When the whole team is able to get together our time is well spent."

"I feel that when we work together and present as a team, parents understand better what is going on with their child. This makes working with some parents easier."

"I think that I work hard to develop positive relationships. I'm happy with my efforts."

"I could do better, but with the limited time that I have, I do the best that I can.”

\section{Phase Three- Combined Focus Group}

The final focus group combined the educators and the related health services

personnel. This group was comprised of the following ten participants:

2-middle school special education teachers (moderate-severe level)

2-high school special education teachers (moderate-severe level)

2-nurses (1-special needs specific)

1-occupational therapist

1-physical therapist

2-speech pathologists

During the final phase of data collection the same set of questions was asked of the combined group that was asked of the separate groups during Phase Two in order to have confirmation of areas of agreement and disagreement. Additional 
questions were more broadly themed and drawn in part from the Guiding Research Questions described in Chapter One and in part as additional follow-up to the original questionnaire. These were purposefully broad questions to permit the respondents wide latitude and discovery of evidence to support or refute identified themes including barriers and opportunities. These questions were as follows:

- In your collaborative capacity at the middle and/or high school level, can you identify unique barriers to collaboration?

- In your collaborative capacity at the middle and/or high school level, can you identify unique opportunities?

- Within your setting are there additional means by which more effective collaboration can be promoted? If so, then what?

Results for Phase Three confirmed all of the themes and findings noted in Phase Two data collection. This may have been due in part to the fact that all of the participants in the final combined focus group had previously participated in the discipline specific groups in Phase Two. After coding the transcripts of the final focus group, it was worth noting that those participating in the combined group upheld the same attitudes and findings expressed previously by their discipline on the original five questions. For the new questions, two additional themes were noted relating to possible barriers to collaboration. The first theme dealt with the low expectations for student progress that leads to frustration and loss of hope that any interventions will be beneficial. The second additional theme was the absence or very limited use of a functional skills curriculum for students with moderate and severe disabilities. Due to the multiplicity of need and the cognitive level of student with moderate and severe 
disabilities, a functional skills curriculum, addressing life skills. requires the input form multiple team members in order to address educational and physical accommodations.

The perspective of hopelessness was represented by two concerns: limitations based on level of disability and length of time that students could attend the high school program. The following quotes reflect this sense of hopelessness.

"I sometimes think that, based on the severity of the disability, people collaborate more or less. What I mean is, for kids who have less severe disabilities, we can generate more ideas for programming. For some kids there is a limitation to what we can do."

"By the time these students get to the high school, everyone has given up hope.”

"At the middle and high school level, we often work on maintenance as opposed to progress."

"People collaborate more at preschool and elementary levels because they are developing new programming. In the upper grades, we are often using the same plan over and over.”

"When you work with the same student for years and see minimal progress, the team often just goes through the motions."

The two teachers and the four therapists participating in the focus group made comments that reflected an additional theme of student programming limitations.

They stated that since the district required educational programming linked to the Ohio Academic Content Standards, there was limited or no use of a functional skills curriculum for students with moderate and severe disabilities. These selected quotes support this theme.

"Our district is so focused on academics they don't realize that these students need functional curriculum. But then again this would require more time to collaborate.” 
"In the middle school we do some collaboration with the consumer science classes but that is because we fought for it."

"At the high school we never get to use the home-ec rooms or borrow the equipment. They say special ed has money- you buy it. So much for teaching something useful.”

“As a therapist, I see IEPs with education goals and no life skills. The district is afraid to use a goal that is not in the content standards. These kids should be working on life skills. It should be all right with the state department- after all, these kids get alternative assessments.”

The combined group was able to identify one unique opportunity for collaboration at the middle and high school level, that of addressing the requirement of transition. However, the special education teachers and related health services personnel expressed that transition was not being addressed adequately. The following quotes support the identification of this unique opportunity.

"These students range from 12 to 22 . We should address transition, but we don't. Or at least not like we are supposed to.”

“Isn't transition required by IDEA? At what ages” (Response provided by me as the facilitator: "Yes. For middle and secondary students, transition is required at ages 14 \& 16.) "Wow, I didn't realize that it was a legal requirement.”

"We do address transition, but usually just on education and legal guardianship for moderate and severe students. We don't do much for transition for independent living or work.”

When asked to generate ideas as to how the district could recognize and reward collaborative efforts, the participants simply stated more time to collaborate would be reward enough. The group also agreed that having students demonstrate success was another reward. The following quotations lend support to these two beliefs. 
"I don't need to have rewards outside of the positive progress of the individual student.”

“True, I am most satisfied when we make progress as a team.”

"Parents leaving a meeting with a better understanding due to correct collaboration is the reward. Everything with these students overlaps and having everyone on the same page is the payoff."

"Reward would be having a scheduled time to collaborate outside of my planning time. I'm constantly tracking down people.”

"OK, it is fine to be happy with student progress, but having time to discuss the student would still be most helpful.”

The final question addressed additional means by which more effective collaboration could be promoted. There was no group consensus, but the following variety of ideas were generated: better use of e-mail and phone calls; time set aside each grading period for the teachers and related health services personnel to get together at the middle and high school; flex time for evening meetings; required training for administrators on the importance of collaboration when serving students with special needs. It should be noted that I inquired about the desirability of additional training in collaboration skills for teachers and related services personnel, but the group agreed that training was not needed as much as time. 


\section{Chapter V}

Discussion

\section{Introduction}

This study was designed to examine the state of ongoing collaborative efforts among special education teachers and related health service personnel in the Springfield City School District in Springfield, Ohio. In particular, I sought answers to six guiding research questions. These were as follows:

1. Are there barriers and opportunities for collaboration that are unique to the middle and high school settings?

2. What are the currently perceived barriers to collaboration between special education teachers and related health service personnel when serving students with moderate and severe disabilities at the middle and high school levels?

3. What are the currently perceived opportunities for collaboration between special education teachers and related health service personnel when serving students with moderate and severe disabilities at the middle and high school levels?

4. Can areas of agreement be identified related to the process of collaboration between special education teachers and related health service personnel when serving students with moderate and severe disabilities at the middle and high school levels?

5. Can areas of disagreement be identified related to the process of collaboration between special education teachers and related health service 
personnel when serving students with moderate and severe disabilities at the middle and high school levels?

6. What specific suggestions can be made to promote more effective collaboration when serving students with moderate and severe disabilities at the middle and high school levels?

To obtain answers to these, I utilized a simple quantitative survey measure combined with a qualitative interview measure consisting of a series of focus groups. The focus groups were used to examine in more detail collaboration at the middle and high school levels when serving students with moderate and severe disabilities. The results fell into three broad categories. The first category consisted of responses for which there was broad agreement related to concepts of collaboration. In the second category were grouped responses addressing specific perceptions and practices at the middle and high school levels. Responses in the final category were those for which there was no general agreement across groups and high variability within groups. From these results, I have drawn conclusions, recommendations, and directions for future research.

Category One

Agreement on Value of Collaboration

Despite differences in training and experience among teachers and related health services personnel, they tended to define common elements of collaborative efforts when serving students with disabilities in the school setting. There were three major areas of agreement. All participants recognized the value of collaboration when serving students and the importance of mutual goals and responsibilities. In addition, 
individuals expressed that they derived personal satisfaction from their participation in "successful" collaborative teams.

These common elements may constitute the driving forces behind continued efforts to participate in collaborative efforts despite a plethora of perceived barriers. These three elements were not only identified by these special education teachers and related health services personnel, but they are also supported in the various definitions of collaboration by Idol, Paolucci-Whitcomb \& Nevin (1994), Mostert (1998), and Friend \& Cook (2003). These definitions all support and identify the requirement that collaboration consist of progress toward shared or common goals, have parity of participation, and be beneficial to the student being served. From this study, it was evident that when collaborating these teachers, therapists, and nurses felt a sense of efficacy based on their efforts. No opportunities were identified by special education teachers or related health services personnel at any level on the questionnaire.

\section{Agreement on Perceived Barriers and Opportunities}

Responses to the questionnaire indicated that the lack of sufficient time was one of the two common barriers identified by all participants. The other common barrier was a lack of sufficient/adequate/appropriate reward and recognition by administrators.

\section{Category Two: Focus on Middle and High School}

This category addresses those issues where significant differences were identified using the questionnaire and further explored in the focus groups. Specific differences existed between special education teachers and related health services 
personnel and/or early and upper grades. These included the following: 1) appropriate team composition; 2) availability of team members; 3) mutual understanding of team members roles and responsibilities, and 4) insufficient administrative understanding and support.

The questionnaire identified team composition and availability of team members to be barriers to collaboration. Focus group discussions revealed that caseloads for the therapists and nurses were onerous and confirmed that appropriate team members were not always available. Consequently, group decisions might be made without one or more of the essential team members present. This problem was exacerbated when scheduling for students, teachers, and therapists became progressively more difficult at the middle and high school. For example, a single nurse may serve all of the students with moderate and severe disabilities across nine schools within the district. This presents this nurse with a myriad of scheduling and availability problems. The therapists are also deliver services across age groups and have to travel throughout the district. This is not an unusual happening in the delivery of services to students with moderate and severe needs. Both the educational and medical literature view this as common practice however, no one states that this type of services delivery is optimal (Heller, Best, Dykes, \& Cohen, 2000).

The questionnaire identified a perception that administrative support was lacking for therapists and special education teachers at the middle and high school levels. This was further explored in the focus groups. The discussion revealed that on contributing factor was the difference in the scheduling of activities at middle and high school versus preschool and elementary. Scheduling at middle and high school 
levels did not provide adequate time to be devoted to planning or executing successful collaboration. Because teacher classroom duties occupied the entire day. Teachers expressed the feeling that this situation was recognized by their disability area special education coordinator, but not by their building principals. In their opinion, principals failed to understand the importance of collaborative planning for the execution of the delivery of educational services. Rather, the completion of required IEPs and assessments was emphasized at the level of the principal.

Both teachers and related health service personnel both expressed the feeling that district and building level administrators were unwilling to hear suggestions and/or follow-up on suggestions directed at remedying this problem. Consequently, teachers and related health services personnel had the perception that their collaborative activities and the delivery of services to students with special needs has a low priority within the Springfield City School District. This perception may impede the implementation of collaborative efforts that constitute recognized best practice. Overall, I sensed a general state of resignation that things would remain the same despite their efforts and wishes. Indeed, this perception on the part of teachers and related health services personnel may have induced in them a state of "learned helplessness" and dulled their incentive and ability to recognize other opportunities. This may be evidenced in the fact that neither teachers nor the related health services personnel identified other opportunities that would lead to improved collaborative team function. 
Category Three: Mixed and conflicting Opinions

Responses in this category displayed a high degree of variability and the maximal possible range. Consequently, the group/participants as a whole had mixed or conflicting opinions. This was true on the following questionnaire statements:

\#4 My concept of collaboration matches that of the therapists with whom I work.

\#8 I have adequate training in methods of collaboration

\#9 Collaboration is critical to meeting the needs of students and families.

\#10 All members of collaborative teams participate equally

\#13 Collaboration is voluntary

\#20 Our school district places high priority on collaborative efforts between teachers and therapists.

\#26 Collaborators are able to maintain professional attitudes; personal differences do not impede the workings of the group.

These results may have been due, in part, to the specific training and experiences of each individual. The differences in the educational and medical models of training and the differences in individual experiences may also have contributed to the high degree of variability of responses. Indeed, upon further exploration of these topics in the focus groups, it was confirmed that, even within a single discipline, the formal training specifically addressing collaboration was highly variable. Not surprisingly, the experience of individual teachers also varied widely. I was surprised to find that there was no agreement within or among the groups on statement \#9: Collaboration is critical to meeting the needs of students and families. Similar statements on the questionnaire elicited general agreement on the value of collaboration as did focus 
group discussions. Perhaps this was due to the phrasing of this statement. In particular I suspect that the use of the word "critical" may be open to varying interpretations.

\section{Summary}

Federal legislation and current best practices demand that education and related health services professionals work together collaboratively. This study was designed to examine the participants' understanding of their roles and responsibilities as well as their beliefs and expectations concerning effective collaborations. Areas of agreement and disagreement among the collaborators were examined in order to identify current barriers to effective collaboration and potential opportunities for better delivery of services through improved collaboration.

Special educators and related service personnel participating in this study agreed, in general, on the definition of interdisciplinary collaboration. This finding differs from the reports of them (Thomas, Correa \& Morsink, 2001; West \& Idol, 1987) that the definition of collaboration often differs between disciplines and that differing definitions lead to misunderstandings between service providers. The present result may be due to the development of a greater emphasis on and acceptance of collaboration in recent years or to better perception of teachers and health related personnel. While the participants in this study mutually agreed on the definition of collaboration, they perceived a lack of support and understanding of collaboration on the part of administrators which they identified as a barrier to the development of better collaborations. It is interesting to speculate that administrators may indeed have a different definition of collaboration and outlook on the benefits of collaborative practice a possibility remains to be investigated. 
Another area of general agreement was the positive perceptions of collaborative efforts with respect to providing student services as well as for personal satisfaction. This positive perception offers an opportunity for further development of collaborative efforts. The participants acknowledged and supported the beneficial outcome of collaboration that allowed participants to have joint ownership of the process and to make use of creative problem solving to improve the services delivered to the students. Such collaborations could then be more effectively directed toward increasing student skills and the level of academic performace. These positive benefits have been noted by many in the field of special education (Dettmer, Thurston \& Dyck 2002; Friend \& Cook, 2000, 2003; Fishbaugh, 1997; Idol, 2002; Mostert, 1998; Thomas, Correa \& Morsink, 2001).

A third area of general agreement among participants involved the constraints of time. Both teachers and related health services personnel reported that finding the time to develop and carryout collaborations was a serious problem. The participants noted issues of scheduling, assignment to multiple buildings, and size of caseloads as determining factors limiting the time available to develop and implement effective collaborations. Over and over in the literature on interdisciplinary collaboration in early intervention and special education programming, time has been noted as a barrier to successful collaboration (Dettmer, Thurston, \& Dyck,2005; Friend \& Cook, 2003; Rainforth, York, \& Macdonald, 1992; Thomas, Correa, \& Morsink, 2001). The results of this study confirmed that time limitations are a major barrier to the development of collaborative relationships. 
From the results of this study, a unique opportunity for improved collaboration when serving students with moderate and severe disabilities at the middle and high school levels was identified. Both special educators and related health services personnel identified transition to be an opportunity. This demonstrates their understanding and commitment to the need for and process of transition. In particular, these participants stressed the importance of collaboration when addressing transition at the ages of fourteen and sixteen. The need for transition was recognized originally by IDEA and most recently in 2004 with its reauthorization. The overall importance of transition at these ages has been recognized and well documented by many authors (Deutsch-Smith, 2005; Heward, 2000; Mastropieri \& Scruggs, 2004; Turnbull, Turnbull, Shank \& Smith 2004). Orelove and Sobsey (2005) and Dettmer, Thurston and Dyck (2005) state the unique needs of individuals with severe and multiple needs for transition services that lead to meaningful and productive lives. Dettmer, Thurston, \& Dyck (2005) state that, "without concerted team effort, students with disabilities will be hard-pressed to make a successful transition to adult life.” (2005, p. 330). The recognition on the part of the participants in this study that transition presented an opportunity for more effective collaboration may lead to better delivery of services during this period.

Despite the existence of several barriers to the development and implementation of effective collaborations, the value of collaboration is recognized by these participants, and they see several opportunities exist to improve collaborations. It is my hope that further research into the collaborations among educators and related health services personnel will address the existing barriers and 
provide the knowledge necessary to tear them down. In addition, novel opportunities to create more effective collaborations must be identified. In this way, collaborations among participants in the fields of medicine and education serving students with moderate and severe disabilities at the middle and high school levels continue to grow more effective. As new approaches are developed, additional benefits will accrue for all involved.

Recommendations

\section{Recommendations for the District}

Based on my review of the data and hearing the voices of the special educators, therapists, and nurses employed by the Springfield City School District, I will make the following recommendations to the district:

- Address the need for an increase in time dedicated to interdisciplinary collaboration. The participants suggested that at least one time per grading period be dedicated to collaborative planning. Another suggestion would be to allow for "flex time" for evening collaboration with professional and families. This of course would require a system for documentation.

- Address how collaboration can support the requirement of transition for students enrolled in middle and secondary programs. This should be a high priority since IDEA legally requires and best practice supports the need for transition, especially for students with moderate and severe needs. This could be carried through by students and parents participating in an "orientation" visit and the high school 
special education teachers spending time observing in the middle school setting for insight on specific student programming. The special education teachers, therapists, and nurses could also meet to specifically develop transition plans.

- Provide training to administrators that addresses the benefits of collaborative practice when serving students with special needs. This training should also present different models of collaboration so that an administrator is better equipped to facilitate collaboration at both the building and district level.

- A review of the curriculum for students with moderate and severe disabilities should also be completed. The teachers and therapist expressed a desire for this review, and they noted that the current academic based curriculum was not addressing the needs of these students.

\section{Recommendations for Policy and Practice}

I can only make limited recommendations for practice at this point in time. This is due in part to the limited comparative body of literature investigating interdisciplinary collaboration when serving students with moderate and severe disabilities at the middle and high school levels. However, I suggest the following:

- Consider the legal requirement of on-going collaborative practice. Even though the law embodies interdisciplinary efforts it does not directly require that such interaction be on-going. Since IDEA mandates transition at ages fourteen and sixteen, perhaps the law 
should delineate who should be involved when a student moves from one grade level to the next, such as middle school to high school. Another consideration for students with moderate and severe disabilities who are typically served in school until the age of twentyone, a third age for transition should be added at age eighteen. This would ensure that "age of majority” be addressed for students and families.

- Incorporate the formal teaching of collaborative practice into undergraduate and graduate level degree programs. In specific, the disciplines should address how to approach collaboration in the inclusive educational setting. Teaching various skills for how to collaborate within and between disciplines would only increase the likelihood that collaboration would be carried out when providing programming for students. Even though this has been stated as a need in the literature, from this study and from my current perspective as an instructor in a university setting, I do not see collaboration being address in the manner in which it should. Perhaps with the 2004 reauthorization of IDEA and with the No Child Left Behind mandate of hiring highly qualified teachers, undergraduate and graduate programs will see the increased need necessity for training in collaboration. 


\section{Limitations}

Given the design of this study and subject population, I recognized that the limitations must be considered and recognized when interpreting, formulating, and applying the results and conclusions. The aim of qualitative research is not the generalization of results to a larger population, but rather the acquisition of an indepth understanding derived from evidence found in separate cases over time (McMillan \& Schumaker, 1993). However, some generalization is possible through the process of extracting common themes from the qualitative data analyses across multiple studies (Miles \& Huberman, 1994, Creswell, 2002). Since this study has not been repeated, the findings are bound to the context in which they were collected and interpreted. In particular, the present study examined only collaboration involving the delivery of service to children with moderate to severe disabilities. Nevertheless, a desired outcome of this study was that it would prove useful to other interested investigators and practitioners and enable them to extend their own investigations and improve their practice.

\section{Future Research}

Several future research questions emerge from the results of this study. First, it is apparent from the results that the collaborating special education teachers and related health service personnel have the perception that administrators in the Springfield City School District place a low value on collaborative efforts. This perception appears to have a dramatic impact on the attitudes and practices of the collaborating special education teachers and related health personnel. An obvious 
follow-up study would involve an examination of the outlook of the district and building administrators with respect to collaboration within their district and schools. At this time, it is not clear whether their outlook and expectations differ from those of the teachers, therapists, and nurses. In such a follow-up study, several areas could be examined with respect to the administrators, including: their definition of collaboration; their opinion of the benefits of collaboration for the students; their perceptions of existing barriers and opportunities to improve and foster collaborative efforts within the schools; and their interpretation of their legal responsibilities to implement collaborative efforts. In some areas, the opinions and perceptions of special education teachers and related health personnel differed across the grade levels. Thus, it is possible the that the attitudes and practices of administrators at pre-school, elementary, middle, and high school levels may also exist and influence the collaborations that occur. Such differences could examined and compared to those of teachers and related health personnel.

This study presents findings based on a narrowly defined population of moderate and severe disabilities. It is possible that the level of participation, attitudes, and perceptions of collaboration among teachers and related health personnel who deliver services to children with mild disabilities differ from those dealing with children with moderate to severe disabilities. Such differences also remain to be examined.

The present study examined a relatively small urban school population. In the future, it may also be of interest to examine collaboration in a rural school population and/or a larger urban school population. 


\section{References}

Aksamit, D.L., \& Rankin, J.L. (1993). Problem solving teams as prereferral process. Special Services in the Schools 7, 1-25.

Allen, K. E., Holm, V. A., \& Schiefelbusch, R. L. (1978). Early intervention: A team approach. Baltimore: University Park Press.

Bahr, M. W., Whitten, E., Dieker, L., Kocarek, C. E., \& Manson, D. (1999). A comparison of school-based intervention teams: Implications for educational and legal reform. Exceptional Children, 66(1), 67-83.

Bailey, D. B., Simeonsson, R. J., Yoder, D. E., \& Huntington, G. S. (1990). Preparing professionals to serve infants and toddlers with handicaps and their families: An integrative analysis across eight disciplines. Exceptional Children, 57(1), 26-34.

Bateman, B. (1995). The physician and the world of special education. Journal of Child Neurology, 10(1), 114-120.

Beck, H. L. (1962). The advantages of a multi-purpose clinic for the mentally retarded. American Journal of Mental Deficiency, 66, 789-794.

Briggs, M. H. (1997). Building early intervention teams: Working together for children and families. Gaithersburg, MD: Aspen.

Brown, L., Branston, M. B., Hamre-Nietupski, S., Pumpian, I., Certo, N., \& Gruenwald, L. (1979). A strategy for developing chronological age appropriate and function curricular content for servele handicapped adolescents and young adults. Journal of Special Education, 13(1), 81-90. 
Cochrane, G. G., Farley, R., \& Wilhelm, I. J. (1990). Preparation of physical therapists to work with handicapped infants and their families: Current status and training needs. Physical Therapy, 70(6), 372-380.

Coben, S. S., Thomas, C. C, Sattler, R. O., \& Morsink, C. V. (1997). Meeting the challenge of consultation and collaboration: Developing interactive teams. Journal of Learning Disabilities, 30 (4), 427-432.

Creswell, J. P. (2002). Educational research: Planning, conducting, and evaluating quantitative and qualitative research. Columbus, $\mathrm{OH}$ : Merrill/Prentice Hall.

Dettmer, P., Thurston, L. P., \& Dyck, N. (2002). Consultation, collaboration, and teamwork for students with special needs. Boston: Allyn and Bacon.

Dettmer, P., Thurston, L. P., \& Dyck, N. (2005). Consultation, collaboration, and teamwork for students with special needs ( $5^{\text {th }}$ ed.) Boston: Allyn and Bacon.

Deutsch-Smith, D. (2004). Introduction to special education: Teaching in an age of Opportunity ( $5^{\text {th }}$ edition) Boston, MA: Pearson Education.

Dinnebeil, L. A., Hale, L. M., \& Rule, S. (1999). Early intervention program practices that support collaboration. Topics in Early Childhood Special Education 19(4), 225-235.

Downing, J.E. (2002). Including students with severe and multiple disabilities in typical classrooms: Practical strategies for teachers ( $2^{\text {nd }}$ ed.). Baltimore: Paul H. Brookes.

Fishbaugh, M. S. E. (1997). Models of collaboration. Boston: Allyn and Bacon. 
Fleming, J. L., \& Monda-Amya, L. E. (2001). Process variables critical for team effectiveness: A Delphi study of wraparound team members. Remedial and Special Education, 22(3) 158-171.

Friend, M., \& Cook, L. (2000). Interactions: Collaboration skills for school professionals ( $3^{\text {rd }}$ ed.). White Plains, NY: Longman.

Friend, M., \& Cook, L. (2003). Interactions: Collaboration skills for school professionals ( $4^{\text {th }}$ ed.). Boston: Allyn and Bacon.

Frankfort-Nachmias, C., \& Nachmias, D. (1996). Research methods in the social sciences $\left(5^{\text {th }}\right.$ ed). New York: St. Martin Press.

Gable, R. A., Henderickson, J. M., \& Rogan, J. P. (1996). TEAMS supporting students at risk in the regular classroom. The Clearing House, 69 (4), 235238.

Gable, R. A., Young, C. C., \& Henderickson, J. M. (1987). Content of special education teacher preparation. Are we headed in the right direction? Teacher Education and Special Education, 10, 135-139.

Golin, A. K., \& Ducanis, A. J.(1981). The interdisciplinary team. Rockville, MD: Aspen.

Grady, M. P. (1998). Qualitative and action research: A practitioner handbook. Bloomington, IN: Phi Delta Kappa Educational Foundation.

Heller, K.W., Fredrick, L.D., Best, S., Dykes, M.K., \& Cohen, E.T. (2000). Specialized health care procedures in the schools: Training and service delivery. Exceptional Children, 66 (2), 173-186. 
Heller, K.W., Fredrick, L., \& Rithmore, N. (1997). Special health care procedures in the schools. Physical Disabilities: Education and Related Services, 14, 5-22.

Heston, M. L., Raschke, D., Kliewer, C., Fitzgerald, L. M., \& Edmiaston, R. (1998). Transforming teacher preparation in early childhood education: Moving to inclusion. Teacher Education and Special Education, 21(4), 278-292.

Heward, W.L. (2000). Exceptional children: An introduction to special education (6 ${ }^{\text {th }}$ ed.). Upper Saddle river, NJ: Merrill.

Howard, V. F., Williams, B. F., Port, P. D., \& Lepper, C. (2001). Very young children with special needs: A formative approach for the $21^{\text {st }}$ century: Upper Saddle River, NJ: Merrill.

Humphry, R., \& Link, S. (1990). Entry level preparation of occupational therapists to work in early intervention programs. American Journal of Occupational Therapy, 44(9), 828-833.

Hunt, P., Doering, K., Hirose-Hatae, J., Maier, J., \& Goetz, L. (2001). Acrossprogram collaboration to support students with and without disabilities in a general education classroom. The Journal of the Association for Persons with Severe Handicaps, 26(4) 240-256.

Hunt, P., Soto, G., Maier, J., \& Doering, K. (2003). Collaborative teaming to support students at risk and students with severe disabilities in general education classrooms. Exceptional Children, 69(3), 315-332.

Husserl, E. [1913] (1962) Ideas. London: George Allen \& Unwin. (Republished, New York: Colliers.)

Idol, L. (1983). Special educator's consultation handbook. Austin, TX: Pro-Ed. 
Idol, L. (2002). Creating collaborative and inclusive schools. Austin, TX: Pro-Ed.

Idol, L., Paolucci-Whitcomb, P., \& Nevin, A. (1986). Collaborative consultation. Rockville, MD: Aspen Systems Corporation.

Idol, L., Necin, A., \& Paolucci-Whitcomb, P. (1994). Collaborative consultation. ( $2^{\text {nd }}$ ed.). Austin, TX: Pro-Ed.

Idol, L. \& West, J.F. (1987). Consultation in special education (Part II): Training and practice. Journal of Learning Disabilities, 20. 474-494.

Irving Independent School District v. Tatro, 486 U.S. 883, 104 S. Ct. 3371 (1984).

Janney, R.E., \& Snell, M. E. (1997). How teachers include students with moderate and severe disabilities in elementary classes: The means and meaning of inclusion. Journal of the Association for Persons with Severe Handicaps 22(3), 159-169.

Johnson, D. W., \& Johnson, F. P. (1991). Joining together, group theory, and group skills ( $4^{\text {th }}$ ed.). Englewood Cliffs, NJ: Prentice Hall.

Kaiser, S. M., \& Woodman, R. W. (1985). Multidisciplinary teams and group decision-making techniques: Possible solutions to decision-making problems. School Psychology Review, 14, 457-470.

Lehr, D.H. (1990). Providing education to students with complex health care needs. Focus on Exceptional Children, 22(7), 1-12.

Lewis, R. F., Tucker, R., Tsao, H., Canaan, E., Bryant, J., Talbot, P., King, D., \& Flyth, M. (1998). Inproving interdisciplinary team process; A practical approach to team development. Journal of Allied Health, 27(2), 89-95. 
Mastropieri, M.A. \& Scruggs, T.E. (2004). The inclusive classroom: Strategies for effective instruction, ( $2^{\text {nd }}$ ed.) Columbus, OH: Merrill Prentice Hall.

McAfee, J. K. (1987). Integrating thereapy services in the school: A model for training educators, administrators, and therapists. Topics in Early Childhood Special Education, 7(3), 116-126

McMillan, J.H., \& Schumaker, S. (1997). Research in education: A conceptual introduction ( $4^{\text {th }}$ ed.) New York: Longman.

Miles, M. B., \& Huberman, A. M. (1994). Qualitative data analysis: An expanded sourcebook ( $2^{\text {nd }}$ ed.). Thousand Oaks, CA: Sage Publications.

Mostert, M.P. (1998). Interprofessional collaboration in schools. Boston: Allyn and Bacon.

Mulligan-Ault, M., Guess, D., Struth, L., \& Thompson, B. (1988). The implementation of health-related procedures in classrooms for students with severe multiple impairments. Journal of the Association for Persons with Severe Handicaps, 13, 100-109.

Ogletree, B. T., Bull, J., Drew, R., \& Lunnen, K.Y. (2001). Team-based service Delivery for students with disabilities: Practice options and guidelines for success. Intervention in School and Clinic, 36(3), 138-145.

Orelove, F. P. \& Sobsey, D. (1987). Educating children with multiple disabilities: A transdisciplinary approach. Baltimore: Paul H. Brookes.

Orelove, F. P., Sobsey, D., \& Silberman, R.K. (2004). Educating children with multiple disabilities: A collaborative approach (4th ed.). Baltimore: Paul H. Brookes. 
Orelove, F. P. \& Sobsey, D. (1991). Educating children with multiple disabilities: A transdisciplinary approach ( $2^{\text {nd }}$ ed.). Baltimore: Paul H. Brookes.

Patton, M. Q. (1990). Qualitative evaluation and research methods (2 ${ }^{\text {nd }}$ ed). Newbury Park, CA: Sage Publications.

Purvis, P., \& Whelan, R. J. (1992), Collaborative planning between pediatricians and special educators. Pediatric Clinics of North America, 39 (3), 451-469.

Rainforth, B., York, J., \& Macdonald, C. (1992). Collaborative teams for students with severe disabilities: Integrating therapy and educational services. Baltimore: Paul H. Brookes.

Rapport, M.J. (1996). Legal guidelines for the delivery of special health care services in schools. Exceptional Children, 62, 537-549.

Rothstein, L. F. (1995). Special education law (2 ${ }^{\text {nd }}$ ed.). New York: Longman.

Sindelar, P. T., Griffin, C. C., Smith, S. W., \& Wantanabe, A. K. (1992). Prereferal intervention: Encouraging notes on preliminary findings. Elementary School Journal, 92, 245-259.

Snell, M. E. (1993). Instruction of students with severe disabilities ( $4^{\text {th }}$ ed.). New York: Macmillan.

Snell, M. E., \& Janney, R.E. (2000). Teachers’ problem-solving about children with moderate and severe disabilities in elementary classrooms. Exceptional Children, 66(4), 472-490.

Stayton, V.D., Whittaker, S., Jones, E., \& Kersting, F. (2001). Interdisciplinary model for the preparation of related services and early intervention personnel. Teacher Education and Special Education, 24(4), 395-401. 
Siders, J. Z., Riall, A., Bennett, T. C., \& Judd, D. (1987). Training of leadership personnel in early intervention: A transdisciplinary approach. Teacher Education and Special Education, 10, 161-170.

Tesch, R. (1990). Qualitative research: Analysis types and software tools. Bristol, PA: The Falmer Press.

Thomas, C. C., Correa, V. I., \& Morsink, C. V. (1995). Interactive teaming: Consultation and collaboration in special programs ( $2^{\text {nd }}$ ed.). Englewood, NJ: Prentice Hall.

Thomas, C. C., Correa, V. I., \& Morsink, C. V. (2001). Interactive teaming: Enhancing programs for students with special needs ( $3^{\text {rd }}$ ed.). Columbus, $\mathrm{OH}$ : Merrill Prentice Hall.

Turnbull, R., Turnbull, A., Shank, M., \& Smith, S.J. (2004). Exceptional lives: Special education in today's schools ( $4^{\text {th }}$ ed.). Columbus, OH: Merrill Prentice Hall.

Van Meter, P., \& Stevens, R. J. (2000). The role of theory in the study of peer collaboration. The Journal of Experimental Education, 69(1), 113-127.

Walther-Thomas, C., Korinek, L., \& McLaughlin, V.L. (1999). Collaboration to support students’ success. Focus on Exceptional Children, 32(3), 10-20.

Whitehouse, F. A. (1951). Teamwork: An approach to a high professional level. Exceptional Children, 18(1), 75-82.

Whitten, E., \& Dieker, L. (1995). Intervention assistance teams: A broader vision. Preventing School Failure, 40, 41-45. 
Winton, P. (1995). A model for supporting higher education faculty in their early intervention personnel preparation roles. Infants and Young Children, 8(3).

Winton, P., \& Mellin, A. (1997). The “ammunition” (data and strategies) you need to promote interdisciplinary preservice training. Paper presented at the annual conference of the Division for Early Childhood of the Council for Exceptional Children. Louisiana: New Orleans.

Wood, M. (1998). Whose job is it anyway? Education roles in inclusion. Exceptional Children, 64(1), 181-195. 


\section{Appendix A-1 \\ Letter Requesting District Support}

March 17, 2004

Frank Schiraldi, Ph.D.

Springfield City School District

Department of School Improvement

49 East College Avenue

Springfield, OH 45501

Dr. Schiraldi,

I am writing to request permission from the Springfield City School District to complete my doctoral research study in your school system. I am completing my studies through West Virginia University in Morgantown, WV, however, I am currently employed at Wittenberg University in the Education Department. I have lived in Springfield for the past two years, and I have had the opportunity to work with the district in providing field experience, student teaching and collaborative presentations through the Springfield-Wittenberg partnership.

My research focuses on the collaborative relationship between special educators and related service providers. In specific my study will investigate the opportunities and barriers to collaboration between special education teachers, occupational therapists, physical therapists, speech/language pathologists, and school nurses at the high school level when serving students with moderate to severe disabilities and learning needs. I can assure you that I will protect the anonymity of the district, as well as the teachers and related service personnel in presentations and any subsequent publications. Should the district grant me permission, I will submit copies of my Institutional Review Board approval from West Virginia University. I will also provide a summary and analysis of the research to the Springfield City School District.

Specifically, I am requesting the following:

1. permission to distribute a broad questionnaire investigating collaboration to all special educators and related health services personnel employed by the district.

2. permission to hold a series of focus groups with selected high school special education teachers and related health services personnel who work with students identified as having moderate to severe learning needs.

I thank you for your consideration of my request. Should you need further information or documentation, please feel free to contact me. I look forward to your reply.

Sincerely,

Sally Brannan

745 Snowhill Boulevard

Springfield, $\mathrm{OH} 45504$

(937) 399-0178 (home)

(937) 327-6334 (work)

cc: Wendy Ford, Director of Human Resources 
Sally Brannan

745 Snowhill Boulevard

Springfield, $\mathrm{OH} 45504$

Ms. Brannan
SCOTI A. SPEARS, Superintendent E-mail Spearss@springfield-city-kl2.oh.us

MICHAEL E. KINNEER, Treasurer E-mail Kinneer@springfield-city.k12.oh.us

BOARD OF EDUCATION TODD JONES, President

CHRISTI LOCKHART, Vice President

JAMES BACON

On behalf of the Springfield City Schools, Mr. Scott Spears, Superintendent, and Dr. Frank Schiraldi, Executive Director of School Improvement, we give you permission for the following:

JAMES L. HUFFMAN REGINA ROLIINS

1. Permission to distribute a broad questionnaire investigating collaboration to all special educators and related health services personnel employed by the district.

2. Permission to hold a series of focus groups with selected high school special education teachers and related health services personnel who work with students identified as having moderate to severe learning needs.

The Springfield City Schools understands that this research study is to be used for the completion of your doctoral studies at West Virginia University and will investigate relationship and collaboration special education teachers, nurses, therapists, and pathologists regarding students with moderate to severe disabilities. You will also provide the district copies of the Institutional Review Board approval and a summary of the research to the Springfield City Schools.

I would like to thank you for your participation with the Springfield City Schools-Wittenberg partnership. The Springfield City Schools values the strong relationship and collaboration it has with higher learning institutions and contributions each partner provides.

Sincerely,

Kraig Hissong

Kraig E. Hissong

Asst. Executive Director of School Improvement

Springfield City Schools

49 E. College Ave.

Springfield, OH 45504 
Appendix B-1

\section{Survey on Interdisciplinary Collaboration}

The following questionnaire investigates collaboration between special educators and related health services personnel (PT, OT, SLP, Nurse). Please answer the questions in light of your position in working with students with special needs.

I am (circle one)

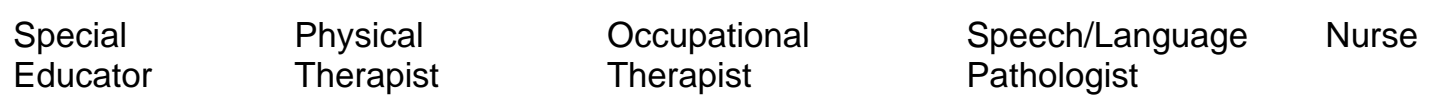

I am currently working at the following level (circle all that apply)

Preschool Elementary School Middle School

High School

For each of the questions below circle the most appropriate response.

Collaboration in My School

1. There is sufficient time in my daily school schedule to develop collaborative interactions.

2. My collaborative efforts are fostered and supported by the administration.

3. Other members of collaborative groups clearly understand their roles and responsibilities.

4. My concept of collaboration matches that of the teachers with whom I work.

5. My concept of collaboration matches that of the therapists with whom I work.

6. Collaboration with others is worth the time and effort in producing optimal outcomes for the student with special needs.

7. Collaboration allows for the generation of creative solutions to issues and problems.

8. I have had adequate training in the methods of collaboration.

9. Collaboration is critical to meeting the needs of students and families.

10. All members of collaborative teams participate equally.

11. Membership on collaborative teams is appropriate at my school.

12. Necessary team members are available to participate in decision making.

\section{Strongly \\ Disagree \\ Agree \\ Disagree}

$$
1
$$

1

1

No

Opinion Agree

Strongly

2

3

4

5

2

3

4

5

2

3

4

5

1

2

3

4

5

1

2

3

4

5

1

2

3

4

5

1

2

3

4

5

1

2

3

4

5

1

2

3

4

5

1

2

3

4

5

1

2

3

4

5

1

2

3

4 


\section{Collaboration in General}

13. Collaboration is voluntary.

Strongly

Disagree

No

Strongly

\section{Agree}

14. Collaboration requires parity (equal participation) among participants.

15. Collaboration is based on mutual goals.

16. Collaborating depends on shared responsibility for participation and decision making.

17. Individuals who collaborate share resources.

18. Individuals who collaborate share accountability for outcomes.

19. My immediate supervisor understands the amount of collaboration required to serve my students.

20. Our school district places a high priority on collaborative efforts between teacher and therapist.

21. I derive personal satisfaction from my collaborative efforts.

22. I am satisfied with my own collaborative efforts.

23. Teachers and therapists are viewed as equal partners in collaborating.

1

2

3

4

5

1

2

3

4

5

1

2

3

4

5

1

1

2

2

$\begin{array}{lll}3 & 4 & 5\end{array}$

1

2

3

4

5

1

2

3

1

2

$\begin{array}{lll}3 & 4 & 5\end{array}$

\section{1}

1

1

1

1

1

1

2

$\begin{array}{lll}3 & 4 & 5\end{array}$

$\begin{array}{lll}3 & 4 & 5\end{array}$

24. Collaboration is recognized and rewarded by my school system.

25. I have ample time and opportunity to develop collaborative relationships.

26. Collaborators are able to maintain professional attitudes; personal differences do not impede the workings of the group.

27. I am aware of the relevant federal legislation that requires collaboration among service providers.

In your own words, how would you define collaboration? 
A. Please elaborate on your thoughts concerning any item(s) on the survey listed above concerning collaboration:

B. Please comment on your perceptions of current barriers for collaboration among special educators and related health service providers. 
Appendix B-2

Questionnaire Letter for Special Educators

April , 2004

Dear Special Educator:

My name is Sara Brannan. I am an Instructor in the Department of Education at Wittenberg University and I am currently working on my dissertation project as part of the requirements for completing my doctoral degree in Special Education and Community Medicine at West Virginia University. My dissertation research project is designed to investigate collaboration among Special Educators and Related Health Service Personnel. Of particular interest are the perceptions of barriers and opportunities for collaborative interdisciplinary efforts. As part of my investigation, I have been given permission by the Springfield City School District to seek your responses to the questions contained in the enclosed survey. In addition, this study has been approved by Exempted Review through the Institutional Review Board at West Virginia University.

I respectfully request that you spend a few moments to complete the enclosed questionnaire and to return it to me in the enclosed stamped envelope.

Thank you for your participation.

Sincerely,

Sara A. Brannan, M.Ed. 
Appendix B-3

Questionnaire Letter for Related Health Service Providers

April , 2004

Dear Related Health Service Provider:

My name is Sara Brannan. I am an Instructor in the Department of Education at Wittenberg University and I am currently working on my dissertation project as part of the requirements for completing my doctoral degree in Special Education and Community Medicine at West Virginia University. My dissertation research project is designed to investigate collaboration among Special Educators and Related Health Service Personnel. Of particular interest are the perceptions of barriers and opportunities for collaborative interdisciplinary efforts. As part of my investigation, I have been given permission by the Springfield City School District to seek your responses to the questions contained in the enclosed survey. In addition, this study has been approved by Exempted Review through the Institutional Review Board at West Virginia University.

I respectfully request that you spend a few moments to complete the enclosed questionnaire and to return it to me in the enclosed stamped envelope.

Thank you for your participation.

Sincerely,

Sara A. Brannan, M.Ed. 


\section{Appendix C}

Focus Groups A-1, A- 2, \& B Focal Topics

(Sample for Prospectus and Institutional Review Board)

The questions/focal topics to be addressed in the discussion items:

Focus Groups 1 \& 2

Focus groups will be derived from the answers/responses to the questionnaire described. (See Appendix A for sample questions.) These questions will address those current barriers and potential opportunities for improved collaboration at the middle and high school levels within the Springfield City Schools.

A list of expected questions and focal discussion items include these listed below. The actual questions and discussion items will be developed following the analysis of the written questionnaire.

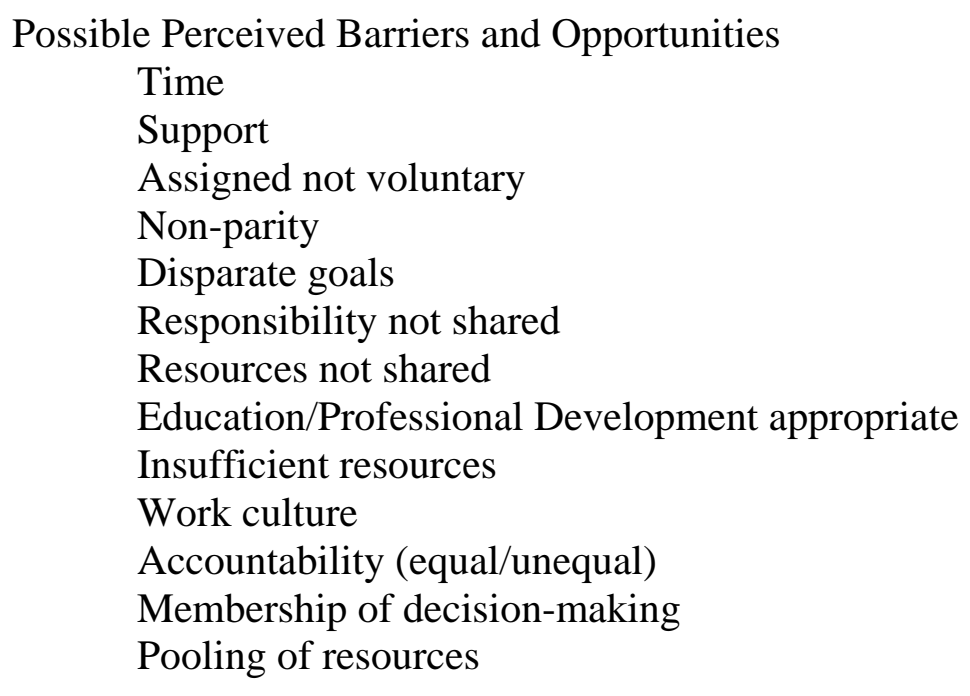


Collaboration106

\section{Appendix D-1}

Focus Groups A-1 \& A-2 Seating Chart

Date:

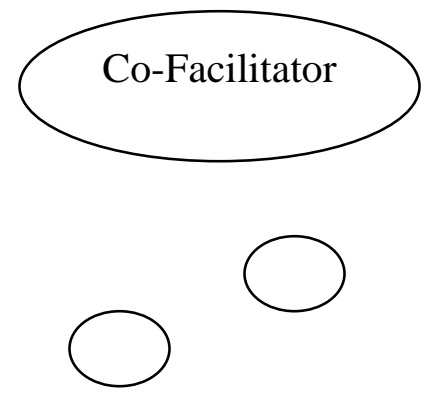

Location:<smiles>C1CCCCCC1</smiles><smiles>C1CCCCCC1</smiles><smiles>C1CCCCCC1</smiles><smiles>C1CCCCCC1</smiles><smiles>C1CCCCCC1</smiles><smiles>C1CCCCCC1</smiles>

Facilitator

Video

Recorder 


\section{Appendix D-2}

\section{Focus Group B Seating Chart}

Date:

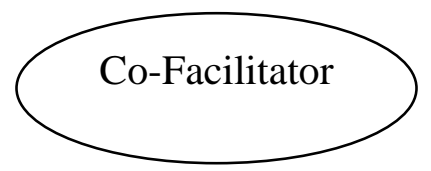

Location:
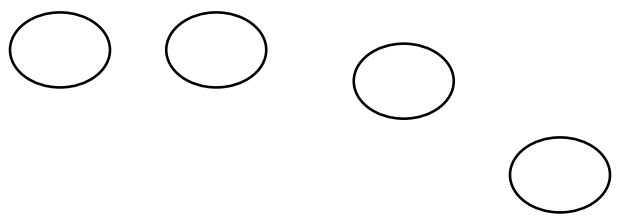

Facilitator

Video

Recorder 
Appendix E

Kruskal-Wallis Test: \#1 versus SPED Level

$\begin{array}{lrrrr}\text { SPED Level } & \mathrm{N} & \text { Median } & \text { Ave Rank } & \mathrm{Z} \\ \text { elementary } & 25 & 2.00 \odot & 43.1 & -0.2 \odot \\ \text { high school } & 13 & 2.00 \odot & 36.0 & -1.24 \\ \text { middle school } & 22 & 2.00 \odot & 44.0 & 0.01 \\ \text { nurse } & 8 & 3.00 \odot & 59.8 & 1.85 \\ \text { preschool } & 7 & 2.00 \odot & 46.6 & 0.29 \\ \text { therapist } & 12 & 2.00 \odot & 42.3 & -0.25 \\ \text { Overall } & 87 & & 44.0 & \\ \mathrm{H}=5.31 \quad \mathrm{DF}=5 \quad \mathrm{P}=0.380 & \text { (adjusted for ties) }\end{array}$

Kruskal-Wallis Test: \#2 versus SPED Level

$\begin{array}{lrrrr}\text { SPED Level } & \mathrm{N} & \text { Median } & \text { Ave Rank } & \mathrm{Z} \\ \text { elementary } & 25 & 4.000 & 45.7 & 0.41 \\ \text { high school } & 13 & 3.000 & 39.2 & -0.74 \\ \text { middle school } & 22 & 3.500 & 37.1 & -1.48 \\ \text { nurse } & 8 & 4.000 & 58.3 & 1.68 \\ \text { preschool } & 7 & 4.000 & 66.4 & 2.44 \\ \text { therapist } & 12 & 3.000 & 35.7 & -1.23 \\ \text { Overall } & 87 & & 44.0 & \\ & & & & \\ \mathrm{H}=13.11 & \text { DF }=5 & \mathrm{P}=0.022 & \text { (adjusted for ties) }\end{array}$

Kruskal-Wallis Test: \#3 versus SPED Level

$\begin{array}{lrrrr}\text { SPED Level } & \mathrm{N} & \text { Median } & \text { Ave Rank } & \mathrm{Z} \\ \text { elementary } & 25 & 4.00 \odot & 51.8 & 1.83 \\ \text { high school } & 13 & 3.00 \odot & 40.0 & -0.61 \\ \text { middle school } & 22 & 3.00 \odot & 32.9 & -2.38 \\ \text { nurse } & 8 & 4.00 \odot & 51.3 & 0.86 \\ \text { preschool } & 7 & 4.00 \odot & 63.1 & 2.08 \\ \text { therapist } & 12 & 2.50 \odot & 36.3 & -1.13 \\ \text { Overall } & 87 & & 44.0 & \\ & & & & \\ \mathrm{H}=14.02 & \text { DF }=5 & \mathrm{P}=0.016 & \text { (adjusted for ties) }\end{array}$

Kruskal-Wallis Test: \#4 versus SPED Level

$\begin{array}{lrrrr}\text { SPED Level } & \mathrm{N} & \text { Median } & \text { Ave Rank } & \mathrm{Z} \\ \text { elementary } & 25 & 4.00 \odot & 49.0 & 1.16 \\ \text { high school } & 13 & 3.00 \odot & 41.5 & -0.38 \\ \text { middle school } & 22 & 3.00 \odot & 35.9 & -1.75 \\ \text { nurse } & 8 & 4.00 \odot & 58.4 & 1.70 \\ \text { preschool } & 7 & 4.00 \odot & 53.4 & 1.03 \\ \text { therapist } & 12 & 2.50 \odot & 36.1 & -1.16 \\ \text { Overall } & 87 & & 44.0 & \\ \text { H }=9.09 \quad \text { DF }=5 & \mathrm{P}=0.105 & \text { (adjusted for ties) }\end{array}$


Kruskal-Wallis Test: \#5 versus SPED Level

$\begin{array}{lrrrr}\text { SPED Level } & \mathrm{N} & \text { Median } & \text { Ave Rank } & \mathrm{Z} \\ \text { elementary } & 25 & 4.00 \odot & 48.0 & 0.95 \\ \text { high school } & 13 & 3.00 \odot & 28.3 & -2.43 \\ \text { middle school } & 22 & 3.00 \odot & 36.9 & -1.53 \\ \text { nurse } & 8 & 4.000 & 54.6 & 1.24 \\ \text { preschool } & 7 & 4.000 & 48.2 & 0.46 \\ \text { therapist } & 12 & 4.000 & 56.2 & 1.80 \\ \text { Overall } & 87 & & 44.0 & \\ \mathrm{H}=13.82 & \text { DF }=5 & \mathrm{P}=0.017 & \text { (adjusted for ties) }\end{array}$

Kruskal-Wallis Test: \#6 versus SPED Level

$\begin{array}{lrrrr}\text { SPED Level } & \mathrm{N} & \text { Median } & \text { Ave Rank } & \mathrm{Z} \\ \text { elementary } & 25 & 5.00 \odot & 42.5 & -0.35 \\ \text { high school } & 13 & 5.00 \odot & 44.3 & 0.04 \\ \text { middle school } & 22 & 5.00 \odot & 42.9 & -0.23 \\ \text { nurse } & 8 & 5.00 \odot & 51.1 & 0.84 \\ \text { preschool } & 7 & 5.00 \odot & 43.7 & -0.03 \\ \text { therapist } & 12 & 5.00 \odot & 44.2 & 0.03 \\ \text { Overall } & 87 & & 44.0 & \\ & & & \\ H=1.04 \quad D F=5 & P=0.960 & \text { (adjusted for ties) }\end{array}$

Kruskal-Wallis Test: \#7 versus SPED Level

$\begin{array}{lrrrr}\text { SPED Level } & \mathrm{N} & \text { Median } & \text { Ave Rank } & \mathrm{Z} \\ \text { elementary } & 25 & 4.00 \odot & 40.7 & -0.78 \\ \text { high school } & 13 & 5.00 \odot & 48.1 & 0.63 \\ \text { middle school } & 22 & 5.00 \odot & 42.7 & -0.28 \\ \text { nurse } & 8 & 5.00 \odot & 46.6 & 0.31 \\ \text { preschool } & 7 & 5.00 \odot & 42.0 & -0.22 \\ \text { therapist } & 12 & 5.00 \odot & 48.3 & 0.64 \\ \text { Overall } & 87 & & 44.0 & \\ \text { H }=1.74 \quad \text { DF }=5 & \mathrm{P}=0.883 & \text { (adjusted for ties) }\end{array}$

Kruskal-Wallis Test: \#8 versus SPED Level

$\begin{array}{lrrrr}\text { SPED Level } & \mathrm{N} & \text { Median } & \text { Ave Rank } & \mathrm{Z} \\ \text { elementary } & 25 & 4.00 \odot & 45.3 & 0.30 \\ \text { high school } & 13 & 4.00 \odot & 42.9 & -0.17 \\ \text { middle school } & 22 & 4.00 \odot & 40.8 & -0.69 \\ \text { nurse } & 8 & 4.00 \odot & 58.2 & 1.67 \\ \text { preschool } & 7 & 3.00 \odot & 41.2 & -0.30 \\ \text { therapist } & 12 & 4.00 \odot & 40.6 & -0.50 \\ \text { Overall } & 87 & & 44.0 & \\ \mathrm{H}=3.67 \quad \text { DF }=5 & \mathrm{P}=0.598 & \text { (adjusted for ties) }\end{array}$


Kruskal-Wallis Test: \#9 versus SPED Level

$\begin{array}{lrrrr}\text { SPED Level } & \mathrm{N} & \text { Median } & \text { Ave Rank } & \mathrm{Z} \\ \text { elementary } & 25 & 5.00 \odot & 43.9 & -0.03 \\ \text { high school } & 13 & 5.00 \odot & 46.4 & 0.37 \\ \text { middle school } & 22 & 4.000 & 41.0 & -0.63 \\ \text { nurse } & 8 & 5.000 & 48.4 & 0.51 \\ \text { preschool } & 7 & 5.000 & 46.1 & 0.23 \\ \text { therapist } & 12 & 4.500 & 43.0 & -0.15 \\ \text { Overall } & 87 & & 44.0 & \\ \mathrm{H}=0.96 \quad \text { DF }=5 & \mathrm{P}=0.966 & \text { (adjusted for ties) }\end{array}$

Kruskal-Wallis Test: \#10 versus SPED Level

$\begin{array}{lrrrr}\text { SPED Level } & \mathrm{N} & \text { Median } & \text { Ave Rank } & \mathrm{Z} \\ \text { elementary } & 25 & 4.000 & 51.4 & 1.74 \\ \text { high school } & 13 & 2.000 & 40.3 & -0.57 \\ \text { middle school } & 22 & 2.000 & 39.1 & -1.06 \\ \text { nurse } & 8 & 2.500 & 47.1 & 0.37 \\ \text { preschool } & 7 & 2.00 \odot & 40.7 & -0.36 \\ \text { therapist } & 12 & 2.00 \odot & 41.4 & -0.38 \\ \text { Overall } & 87 & & 44.0 & \\ & & & \end{array}$

Kruskal-Wallis Test: \#11 versus SPED Level

$\begin{array}{lrrrr}\text { SPED Level } & \mathrm{N} & \text { Median } & \text { Ave Rank } & \mathrm{Z} \\ \text { elementary } & 25 & 3.00 \odot & 36.5 & -1.75 \\ \text { high school } & 13 & 4.00 \odot & 42.0 & -0.32 \\ \text { middle school } & 22 & 4.00 \odot & 38.7 & -1.13 \\ \text { nurse } & 8 & 4.00 \odot & 6 \odot . \odot & 1.88 \\ \text { preschool } & 7 & 4.00 \odot & 59.0 & 1.64 \\ \text { therapist } & 12 & 4.00 \odot & 52.0 & 1.18 \\ \text { Overall } & 87 & & 44.0 & \\ & & & & \\ \mathrm{H}=11.45 & \text { DF }=5 & \mathrm{P}=0.043 & \text { (adjusted for ties) }\end{array}$

Kruskal-Wallis Test: \#12 versus SPED Level

$\begin{array}{lrrrr}\text { SPED Level } & \mathrm{N} & \text { Median } & \text { Ave Rank } & \mathrm{Z} \\ \text { elementary } & 25 & 4.000 & 48.5 & 1.05 \\ \text { high school } & 13 & 3.000 & 34.2 & -1.52 \\ \text { middle school } & 22 & 2.000 & 33.0 & -2.37 \\ \text { nurse } & 8 & 4.000 & 61.4 & 2.05 \\ \text { preschool } & 7 & 4.000 & 58.1 & 1.54 \\ \text { therapist } & 12 & 3.500 & 45.7 & 0.25 \\ \text { Overall } & 87 & & 44.0 & \\ \text { H=14.13 DF }=5 & \mathrm{P}=0.015 & \text { (adjusted for ties) }\end{array}$


Kruskal-Wallis Test: \#13 versus SPED Level

$\begin{array}{lrrrr}\text { SPED Level } & \mathrm{N} & \text { Median } & \text { Ave Rank } & \mathrm{Z} \\ \text { elementary } & 25 & 4.00 \odot & 44.3 & 0.08 \\ \text { high school } & 13 & 3.00 \odot & 38.6 & -0.84 \\ \text { middle school } & 22 & 3.00 \odot & 38.8 & -1.11 \\ \text { nurse } & 8 & 4.000 & 51.4 & 0.87 \\ \text { preschool } & 7 & 2.00 \odot & 40.1 & -0.43 \\ \text { therapist } & 12 & 4.000 & 56.0 & 1.78 \\ \text { Overall } & 87 & & 44.0 & \\ \mathrm{H}=5.96 \quad \text { DF }=5 & \mathrm{P}=0.310 & \text { (adjusted for ties) }\end{array}$

Kruskal-Wallis Test: \#14 versus SPED Level

$\begin{array}{lrrrr}\text { SPED Level } & \mathrm{N} & \text { Median } & \text { Ave Rank } & \mathrm{Z} \\ \text { elementary } & 25 & 4.00 \odot & 45.5 & 0.36 \\ \text { high school } & 13 & 4.0 \odot \odot & 43.7 & -0.04 \\ \text { middle school } & 22 & 4.00 \odot & 49.8 & 1.24 \\ \text { nurse } & 8 & 2.50 \odot & 30.3 & -1.61 \\ \text { preschool } & 7 & 2.00 \odot & 27.2 & -1.83 \\ \text { therapist } & 12 & 4.00 \odot & 49.5 & 0.81 \\ \text { Overall } & 87 & & 44.0 & \\ & & & \\ \mathrm{H}=8.39 \quad \mathrm{DF}=5 & \mathrm{P}=0.136 & \text { (adjusted for ties) }\end{array}$

Kruskal-Wallis Test: \#15 versus SPED Level

$\begin{array}{lrrrr}\text { SPED Level } & \mathrm{N} & \text { Median } & \text { Ave Rank } & \mathrm{Z} \\ \text { elementary } & 25 & 4.00 \odot & 44.5 & 0.11 \\ \text { high school } & 13 & 4.000 & 43.5 & -0.08 \\ \text { middle school } & 22 & 4.00 \odot & 47.0 & 0.64 \\ \text { nurse } & 8 & 4.000 & 47.3 & 0.38 \\ \text { preschool } & 7 & 4.000 & 38.8 & -0.57 \\ \text { therapist } & 12 & 4.000 & 39.0 & -0.74 \\ \text { Overall } & 87 & & 44.0 & \\ \mathrm{H}=1.70 \quad \text { DF }=5 & \mathrm{P}=0.889 & \text { (adjusted for ties) }\end{array}$

Kruskal-Wallis Test: \#16 versus SPED Level

$\begin{array}{lrrrr}\text { SPED Level } & N & \text { Median } & \text { Ave Rank } & Z \\ \text { elementary } & 25 & 4.00 \odot & 41.5 & -0.58 \\ \text { high school } & 13 & 4.00 \odot & 44.3 & 0.04 \\ \text { middle school } & 22 & 4.00 \odot & 44.3 & 0.06 \\ \text { nurse } & 8 & 4.00 \odot & 41.9 & -0.25 \\ \text { preschool } & 7 & 4.00 \odot & 42.3 & -0.19 \\ \text { therapist } & 12 & 4.00 \odot & 50.8 & 1.00 \\ \text { Overall } & 87 & & 44.0 & \\ \text { H }=1.53 \quad \text { DF }=5 \quad \mathrm{P}=0.910 & \text { (adjusted for ties) }\end{array}$


Kruskal-Wallis Test: \#17 versus SPED Level

$\begin{array}{lrrrr}\text { SPED Level } & \mathrm{N} & \text { Median } & \text { Ave Rank } & \mathrm{Z} \\ \text { elementary } & 25 & 4.00 \odot & 41.3 & -0.64 \\ \text { high school } & 13 & 4.00 \odot & 48.1 & 0.64 \\ \text { middle school } & 22 & 4.00 \odot & 44.8 & 0.18 \\ \text { nurse } & 8 & 4.000 & 53.3 & 1.09 \\ \text { preschool } & 7 & 4.00 \odot & 45.1 & 0.12 \\ \text { therapist } & 12 & 4.000 & 37.0 & -1.04 \\ \text { Overall } & 87 & & 44.0 & \\ \mathrm{H}=3.66 \quad \text { DF }=5 & \mathrm{P}=0.599 & \text { (adjusted for ties) }\end{array}$

Kruskal-Wallis Test: \#18 versus SPED Level

$\begin{array}{lrrrr}\text { SPED Level } & \mathrm{N} & \text { Median } & \text { Ave Rank } & \mathrm{Z} \\ \text { elementary } & 25 & 4.00 \odot & 45.5 & 0.36 \\ \text { high school } & 13 & 4.0 \odot \odot & 48.1 & 0.63 \\ \text { middle school } & 22 & 4.00 \odot & 39.6 & -0.94 \\ \text { nurse } & 8 & 4.00 \odot & 44.0 & 0.0 \odot \\ \text { preschool } & 7 & 4.00 \odot & 52.0 & 0.87 \\ \text { therapist } & 12 & 4.0 \odot \odot & 39.7 & -0.63 \\ \text { Overall } & 87 & & 44.0 & \\ & & & \\ H=2.62 \quad D F=5 & P=0.759 & \text { (adjusted for ties) }\end{array}$

Kruskal-Wallis Test: \#19 versus SPED Level

$\begin{array}{lrrrr}\text { SPED Level } & \mathrm{N} & \text { Median } & \text { Ave Rank } & \mathrm{Z} \\ \text { elementary } & 25 & 4.00 \odot & 41.6 & -0.56 \\ \text { high school } & 13 & 3.00 \odot & 37.8 & -0.96 \\ \text { middle school } & 22 & 4.00 \odot & 47.1 & 0.67 \\ \text { nurse } & 8 & 4.00 \odot & 53.4 & 1.11 \\ \text { preschool } & 7 & 4.00 \odot & 56.8 & 1.40 \\ \text { therapist } & 12 & 3.00 \odot & 36.3 & -1.14 \\ \text { Overall } & 87 & & 44.0 & \\ \text { H }=5.99 \quad \text { DF }=5 \quad \mathrm{P}=0.307 & \text { (adjusted for ties) }\end{array}$

Kruskal-Wallis Test: \#20 versus SPED Level

$\begin{array}{lrrrr}\text { SPED Level } & \mathrm{N} & \text { Median } & \text { Ave Rank } & \mathrm{Z} \\ \text { elementary } & 25 & 2.00 \odot & 41.0 & -0.69 \\ \text { high school } & 13 & 3.00 \odot & 42.5 & -0.24 \\ \text { middle school } & 22 & 2.00 \odot & 38.5 & -1.17 \\ \text { nurse } & 8 & 4.00 \odot & 65.5 & 2.53 \\ \text { preschool } & 7 & 3.00 \odot & 48.3 & 0.47 \\ \text { therapist } & 12 & 2.500 & 45.0 & 0.15 \\ \text { Overall } & 87 & & 44.0 & \\ \text { H }=7.95 \quad \text { DF }=5 \quad \mathrm{P}=0.159 & \text { (adjusted for ties) }\end{array}$


Kruskal-Wallis Test: \#21 versus SPED Level

$\begin{array}{lrrrr}\text { SPED Level } & \mathrm{N} & \text { Median } & \text { Ave Rank } & \mathrm{Z} \\ \text { elementary } & 25 & 4.00 \odot & 42.0 & -0.46 \\ \text { high school } & 13 & 4.00 \odot & 38.9 & -0.79 \\ \text { middle school } & 22 & 4.00 \odot & 36.5 & -1.62 \\ \text { nurse } & 8 & 4.500 & 63.5 & 2.29 \\ \text { preschool } & 7 & 4.00 \odot & 56.6 & 1.37 \\ \text { therapist } & 12 & 4.00 \odot & 47.2 & 0.47 \\ \text { Overall } & 87 & & 44.0 & \\ \mathrm{H}=11.83 \quad \text { DF }=5 & \mathrm{P}=0.037 & \text { (adjusted for ties) }\end{array}$

Kruskal-Wallis Test: \#22 versus SPED Level

$\begin{array}{lrrrr}\text { SPED Level } & \mathrm{N} & \text { Median } & \text { Ave Rank } & \mathrm{Z} \\ \text { elementary } & 25 & 4.000 & 43.1 & -0.21 \\ \text { high school } & 13 & 4.000 & 37.6 & -0.99 \\ \text { middle school } & 22 & 4.000 & 44.4 & 0.09 \\ \text { nurse } & 8 & 4.000 & 62.6 & 2.19 \\ \text { preschool } & 7 & 4.000 & 52.9 & 0.97 \\ \text { therapist } & 12 & 3.500 & 34.5 & -1.40 \\ \text { Overall } & 87 & & 44.0 & \\ \mathrm{H}=9.83 \quad \mathrm{DF}=5 & \mathrm{P}=0.080 & \text { (adjusted for ties) }\end{array}$

Kruskal-Wallis Test: \#23 versus SPED Level

$\begin{array}{lrrrr}\text { SPED Level } & \mathrm{N} & \text { Median } & \text { Ave Rank } & \mathrm{Z} \\ \text { elementary } & 25 & 4.00 \odot & 46.5 & 0.59 \\ \text { high school } & 13 & 3.00 \odot & 35.2 & -1.36 \\ \text { middle school } & 22 & 3.00 \odot & 35.7 & -1.79 \\ \text { nurse } & 8 & 4.00 \odot & 54.9 & 1.28 \\ \text { preschool } & 7 & 5.00 \odot & 70.4 & 2.88 \\ \text { therapist } & 12 & 3.500 & 41.0 & -0.45 \\ \text { Overall } & 87 & & 44.0 & \\ & & & & \\ \mathrm{H}=15.18 & \text { DF }=5 & \mathrm{P}=0.010 & \text { (adjusted for ties) }\end{array}$

Kruskal-Wallis Test: \#24 versus SPED Level

$\begin{array}{lrrrr}\text { SPED Level } & \mathrm{N} & \text { Median } & \text { Ave Rank } & \mathrm{Z} \\ \text { elementary } & 25 & 2.00 \odot & 42.6 & -0.33 \\ \text { high school } & 13 & 3.00 \odot & 44.3 & 0.05 \\ \text { middle school } & 22 & 2.00 \odot & 41.8 & -0.48 \\ \text { nurse } & 8 & 3.50 \odot & 62.3 & 2.14 \\ \text { preschool } & 7 & 3.00 \odot & 56.6 & 1.37 \\ \text { therapist } & 12 & 2.000 & 31.1 & -1.90 \\ \text { Overall } & 87 & & 44.0 & \\ \text { H }=9.98 \quad \text { DF }=5 \quad \mathrm{P}=0.076 & \text { (adjusted for ties) }\end{array}$


Kruskal-Wallis Test: \#25 versus SPED Level

$\begin{array}{lrrrr}\text { SPED Level } & \mathrm{N} & \text { Median } & \text { Ave Rank } & \mathrm{Z} \\ \text { elementary } & 25 & 2.00 \odot & 47.3 & 0.76 \\ \text { high school } & 13 & 1.00 \odot & 32.2 & -1.83 \\ \text { middle school } & 22 & 2.00 \odot & 42.1 & -0.4 \odot \\ \text { nurse } & 8 & 3.00 \odot & 61.8 & 2.09 \\ \text { preschool } & 7 & 2.00 \odot & 40.6 & -0.37 \\ \text { therapist } & 12 & 2.00 \odot & 43.5 & -0.07 \\ \text { Overall } & 87 & & 44.0 & \\ \mathrm{H}=8.71 \quad \text { DF }=5 & \mathrm{P}=0.121 & \text { (adjusted for ties) }\end{array}$

Kruskal-Wallis Test: \#26 versus SPED Level

$\begin{array}{lrrrr}\text { SPED Level } & \mathrm{N} & \text { Median } & \text { Ave Rank } & \mathrm{Z} \\ \text { elementary } & 25 & 4.00 \odot & 48.1 & 0.97 \\ \text { high school } & 13 & 4.00 \odot & 46.4 & 0.38 \\ \text { middle school } & 22 & 2.00 \odot & 30.9 & -2.81 \\ \text { nurse } & 8 & 4.000 & 51.9 & 0.93 \\ \text { preschool } & 7 & 4.00 \odot & 47.4 & 0.37 \\ \text { therapist } & 12 & 3.500 & 49.5 & 0.81 \\ \text { Overall } & 87 & & 44.0 & \\ \text { H }=9.25 \quad \text { DF }=5 \quad \mathrm{P}=0.100 & \text { (adjusted for ties) }\end{array}$

Kruskal-Wallis Test: \#27 versus SPED Level

$\begin{array}{lrrrr}\text { SPED Level } & \mathrm{N} & \text { Median } & \text { Ave Rank } & \mathrm{Z} \\ \text { elementary } & 25 & 3.00 \odot & 44.5 & 0.11 \\ \text { high school } & 13 & 4.000 & 50.7 & 1.04 \\ \text { middle school } & 22 & 4.000 & 46.0 & 0.43 \\ \text { nurse } & 8 & 3.000 & 37.9 & -0.72 \\ \text { preschool } & 7 & 4.000 & 48.6 & 0.51 \\ \text { therapist } & 12 & 2.500 & 33.4 & -1.56 \\ \text { Overall } & 87 & & 44.0 & \\ \mathrm{H}=4.20 \quad \text { DF }=5 & \mathrm{P}=0.521 & \text { (adjusted for ties) }\end{array}$




\section{WestVirginiaUniversity}

\section{Office of Research Compliance}

DATE: June 18, 2004

This research will be monitored for re-approval annually. APPROVAL PERIOD: June 18, 2004 to June 17, 2005

NOTICE OF APPROVAL FOR PROTOCOL: IRB \#16273

TO: Sara Brannan

TITLE: An Exploration of Interdisciplinary Collaboration when Serving Students with Moderate and Sever Disabilities at the Middle and High School Levels: A Current Snapshot of Perceived Barriers and Opportunities

AGENCY: N/A

The Institutional Review Board for the Protection of Human Research subjects (IRB) has approved the project described above. Approval was based on the descriptive material and procedures you submitted for review. Should any changes in your protocol/consent form be necessary, prior approval must be obtained from the IRB.

According to the Code of Federal Regulations, Section 312.32, investigators are required to notify the FDA and the study sponsor of any adverse experience associated with the use of an investigational drug that is serious and unexpected. A serious adverse experience is considered any event that is fatal or life-threatening, is permanently disabling, requires inpatient hospitalization, or is a congenital anomaly, cancer, or overdose. An unexpected adverse experience is an event that is not identified in nature, severity, or frequency in the current investigator brochure. Any experience reportable to FDA and the sponsor must also be reported immediately to the IRB. If the study is funded, initiation of the protocol may not begin until the contract is finalized. 
Date: June 18, 2004

Page -2-

Brannan

IRB \#16273

A consent form* $\mathrm{X}$ is___ is not required of each subject. An assent form__ is_ $\mathrm{X}$ is not required of each subject.

A recruitment ad has__ has not__been approved.

A consent form waiver has_ has not_ $\mathrm{X}$ been approved.

An authorization form to use PHI has__ has not $\mathrm{X}$ been approved.

A PHI waiver has__ has not $\mathrm{X}$ been approved.

Only copies of the consent and/or assent form with the IRB's approval stamp may be used with human subject research. It is the responsibility of the investigator to submit a revised consent form for the IRB's approval should funding be obtained. This stamped consent form must then be used for subjects enrolled. A copy of each subject's signed Consent/Assent Form must be retained by the investigator and accessible to federal regulatory authorities for at least three years after the study is completed.

\section{Lilo A. Ast .}

Senior Program Coordinator for

Research Compliance 


\section{Consent and Information Form for}

\section{Participating Special Educators}

\section{AN EXPLORATION OF INTERDISCIPLINARY COLLABORATION WHEN SERVING STUDEN'TS WITH MODERATE AND SEVERE DISABILITIES AT THE MIDDLE AND HIGH SCHOOL LEVELS: A CURRENT SNAPSHOT OF PERCEIVED BARRIERS AND OPPORTUNITIES}

Introduction: I have been asked to participate in this research study which has been explained to me by Sara A. Brannan, doctoral student in Special Education. This research is being conducted at West Virginia University as a dissertation project by Sara A. Brannan.

Purpose of the Study: The purpose of this study is to investigate current perceptions of the barriers and the opportunities for interdisciplinary collaboration among Special Educators and Related Health Service Personnel at the middle and high school levels when serving students with moderate and severe disabilities.

Description of Procedures: I am being asked to participate in two Focus Groups Sessions to be conducted during a three week period. The first of the two Focus Groups will be comprised of 8 to 12 Special Educators only. A combination of 8-12 Special Educators and Related Health Service Personnel will be participants in the second of the two Focus Groups. Each of the focus group sessions will be no more than two hours in duration.

Risk and Discomfort: There are no known or anticipated risks to participants in these focus groups.

Alternative: I understand that I do not have to participate in this study.

Benefits: I understand that the results of this study are to be the subject of the doctoral dissertation of Sara A. Brannan. In addition, I may also derive potential benefit from my participation in the form of greater insight into my professional career planning and choices. I will receive no payment except for food and beverages to be served during the Focus Group Sessions.

Contact Persons: For more information about this research, I may contact Sara A. Brannan at 937-399-0178 or her Dissertation Committee Chair, Dr. Barbara Ludlow at 304-293-3450. For information regarding my rights as a research subject, I may contact the Executive Secretary of the West Virginia University Institutional Review Board at 304-293-7073.

\begin{tabular}{ccc}
$\begin{array}{c}\text { submission date } \\
6 / 17 / 2004\end{array}$ & 1 of 2 & $\begin{array}{l}\text { initial } \\
\text { date }\end{array}$ \\
Curriculum \& Instruction & Literacy Studies & Speciall Education \\
\hline $304293-3441$ & $304293-4769$ & $304293-3450$ \\
Fax: $304293-3802$ & & Fax: $304293-6834$
\end{tabular}


Confidentiality: I understand and have been assured that any information about me or my students obtained as a result of my participation in this research study will be kept in strict confidence within legal limits. My name or identifying information, as well as, that of other participants or students, will not be used in any publications that result from this study without written consent of the principle party or parties. I also understand that any records generated during this study may be subpoenaed, like hospital records, by court order or inspected by federal regulatory authorities.

Voluntary Participation: My participation in this research study is totally voluntary. I understand that I am free to withdraw my consent to participate at any time. Such withdrawal of consent will involve no penalties or losses to me. I have been given the opportunity to ask questions about this research, and I have received answers to my questions. My signature below signifies my willingness and consent to participate. Upon signing this form, I will receive a copy.

Signature of Special Educator Participant:

DATE:

Signature of Principle Investigator:

(Sara A. Brannan, M.Ed.)

DATE:

initial 
WEST VIRGINIA UNIVERSITY West Virginia University

\section{Consent and Information Form}

for Protection of Human Research Subjects

\section{Participating Related Health Service Personnel}

\section{AN EXPLORATION OF INTERDISCIPLINARY COLLABORATION WHEN SERVING STUDENTS WITH MODERATE AND SEVERE DISABILITIES AT THE MIDDLE AND HIGH SCHOOL LEVELS: A CURRENT SNAPSHOT OF PERCEIVED BARRIERS AND OPPORTUNITIES}

Introduction: I have been asked to participate in this research study which has been explained to me by Sara A. Brannan, doctoral student in Special Education. This research is being conducted at West Virginia University as a dissertation project by Sara A. Brannan.

Purpose of the Study: The purpose of this study is to investigate current perceptions of the barriers and the opportunities for interdisciplinary collaboration among Special Educators and Related Health Service Personnel at the middle and high school levels when serving students with moderate and severe disabilities.

Description of Procedures: I am being asked to participate in two Focus Groups Sessions to be conducted during a three week period. The first of the two Focus Groups will be comprised of 8 to 12 Related Health Service Personnel only. A combination of 8-12 Special Educators and Related Health Service Personnel will be participants in the second of the two Focus Groups. Each of the focus group sessions will be no more than two hours in duration.

Risk and Discomfort: There are no known or anticipated risks to participants in these focus groups.

Alternative: I understand that I do not have to participate in this study.

Benefits: I understand that the results of this study are to be the subject of the doctoral dissertation of Sara A. Brannan. In addition, I may also derive potential benefit from my participation in the form of greater insight into my professional career planning and choices. I will receive no payment except for food and beverages to be served during the Focus Group Sessions.

Contact Persons: For more information about this research, I may contact Sara A. Brannan at 937-399-0178 or her Dissertation Committee Chair, Dr. Barbara Ludlow at 304-293-3450. For information regarding my rights as a research subject, I may contact the Executive Secretary of the West Virginia University Institutional Review Board at 304-293-7073.

submission date 1 of 2

$6 / 17 / 2004$
Literacy Studies

304 293-3441 Fax: 304 293-3802

Curriculum \& Instruction
$304293-4769$

$304293-4769$

initial

date 
Confidentiality: I understand and have been assured that any information about me or my students obtained as a result of my participation in this research study will be kept in strict confidence within legal limits. My name or identifying information, as well as, that of other participants or students, will not be used in any publications that result from this study without written consent of the principle party or parties. I also understand that any records generated during this study may be subpoenaed, like hospital records, by court order or inspected by federal regulatory authorities.

Voluntary Participation: My participation in this research study is totally voluntary. I understand that I am free to withdraw my consent to participate at any time. Such withdrawal of consent will involve no penalties or losses to me. I have been given the opportunity to ask questions about this research, and I have received answers to my questions. My signature below signifies my willingness and consent to participate. Upon signing this form, I will receive a copy.

Signature of Related Health Service Personnel Participant:

DATE:

Signature of Principle Investigator:

(Sara A. Brannan, M.Ed.)

DATE:

submission date 2 of 2

$6 / 17 / 2004$

initial

date 
Collaboration121

List of Tables

Table 1 Questionnaire Participants

Table 2 Questionnaire Statements Rounded Agreement, Disagreement, 48 and No Consensus 
Collaboration122

\section{List of Figures}

Figure 1 Structure of Research Design

Figure 2 Data Collection and Coding 